\title{
Metagenomic identification of active methanogens and methanotrophs in serpentinite springs of the Voltri Massif, Italy
}

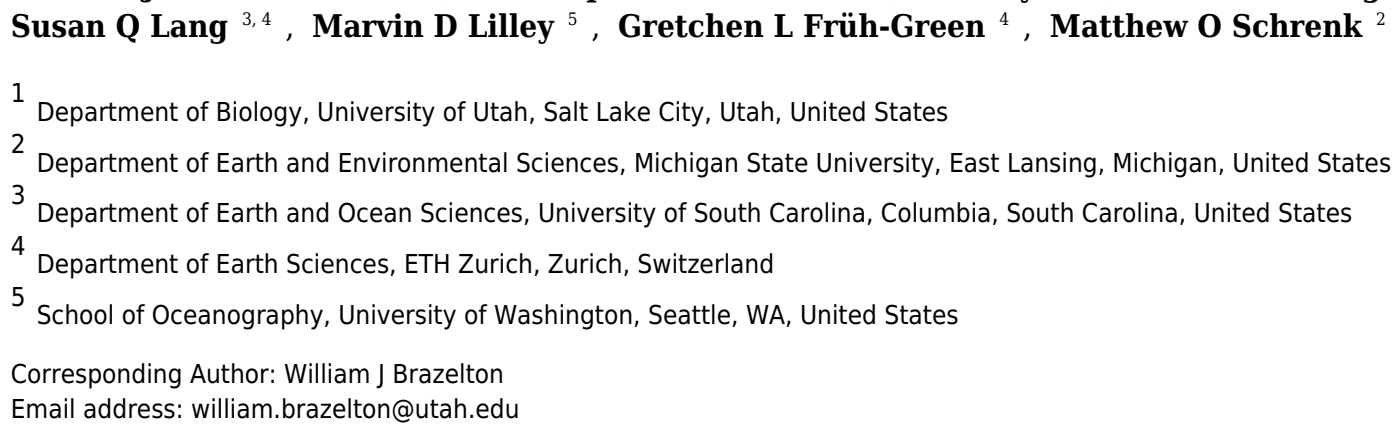

The production of hydrogen and methane by geochemical reactions associated with the serpentinization of ultramafic rocks can potentially support subsurface microbial ecosystems independent of the photosynthetic biosphere. Methanogenic and methanotrophic microorganisms are abundant in marine hydrothermal systems heavily influenced by serpentinization, but evidence for methane-cycling archaea and bacteria in continental serpentinite springs has been limited. This report provides metagenomic and experimental evidence for active methanogenesis and methanotrophy by microbial communities in serpentinite springs of the Voltri Massif, Italy. Methanogens belonging to family Methanobacteriaceae and methanotrophic bacteria belonging to family Methylococcaceae were heavily enriched in three ultrabasic springs ( $\mathrm{pH} 12$ ). Metagenomic data also suggest the potential for hydrogen oxidation, hydrogen production, carbon fixation, fermentation, and organic acid metabolism in the ultrabasic springs. The predicted metabolic capabilities are consistent with an active subsurface ecosystem supported by energy and carbon liberated by geochemical reactions within the serpentinite rocks of the Voltri Massif. 
1 Metagenomic identification of active methanogens and methanotrophs in serpentinite

2 springs of the Voltri Massif, Italy

4 William J. Brazelton ${ }^{1}$, Christopher N. Thornton ${ }^{1}$, Alex Hyer ${ }^{1}$, Katrina I. Twing ${ }^{2}$, August A.

5 Longino $^{1}$, Susan Q. Lang ${ }^{3,5}$, Marvin D. Lilley ${ }^{4}$, Gretchen L. Früh-Green ${ }^{5}$, Matthew O. Schrenk ${ }^{2}$

$7 \quad{ }^{1}$ Department of Biology, University of Utah, Salt Lake City, UT, USA

8 2Department of Earth and Environmental Sciences, Michigan State University, East Lansing, MI, 9 USA

$10{ }^{3}$ Department of Earth and Ocean Sciences, University of South Carolina, Columbia, SC, USA

$11{ }^{4}$ School of Oceanography, University of Washington, Seattle, WA, USA

$12{ }^{5}$ Department of Earth Sciences, ETH Zurich, Zurich, Switzerland

14 Corresponding author:

15 William J. Brazelton

16 Department of Biology

17 University of Utah

18257 South 1400 East, Rm. 201

19 Salt Lake City, UT 84112-0840

$20 \quad(801) 587-9455$

21 william.brazelton@utah.edu 


\section{Abstract}

27 The production of hydrogen and methane by geochemical reactions associated with the

28 serpentinization of ultramafic rocks can potentially support subsurface microbial ecosystems

29 independent of the photosynthetic biosphere. Methanogenic and methanotrophic microorganisms

30 are abundant in marine hydrothermal systems heavily influenced by serpentinization, but

31 evidence for methane-cycling archaea and bacteria in continental serpentinite springs has been

32 limited. This report provides metagenomic and experimental evidence for active methanogenesis

33 and methanotrophy by microbial communities in serpentinite springs of the Voltri Massif, Italy.

34 Methanogens belonging to family Methanobacteriaceae and methanotrophic bacteria belonging

35 to family Methylococcaceae were heavily enriched in three ultrabasic springs ( $\mathrm{pH} 12)$.

36 Metagenomic data also suggest the potential for hydrogen oxidation, hydrogen production,

37 carbon fixation, fermentation, and organic acid metabolism in the ultrabasic springs. The

38 predicted metabolic capabilities are consistent with an active subsurface ecosystem supported by

39 energy and carbon liberated by geochemical reactions within the serpentinite rocks of the Voltri

40 Massif.

41

42

43

44

45

46

47 


\section{Introduction}

52 Hydrothermal systems hosted in ultramafic rocks rich in serpentine minerals can support active 53 and unique microbial communities (see Schrenk, Brazelton \& Lang, 2011 for review). Microbial 54 ecosystems associated with serpentinization (the process by which serpentine is formed) have

55 been investigated by sampling seafloor hydrothermal chimneys (e.g. Kelley et al., 2005;

56 Quéméneur et al., 2014), alkaline springs on land (Brazelton et al., 2013; Suzuki et al., 2013;

57 Woycheese et al., 2015), and wells drilled into serpentinizing rocks (Tiago \& Veríssimo, 2013;

58 Cardace et al., 2013; Crespo-Medina et al., 2014). The microbial inhabitants of these

59 environments are thought to feed on the hydrogen gas and organic compounds released as

60 byproducts of serpentinization, but representative examples of specific organisms consuming

61 specific products of serpentinization are lacking. For example, methane is typically abundant in

62 serpentinite-hosted hydrothermal systems, but only a few studies have provided evidence for

63 methanogenic or methanotrophic biological activity in such systems (Brazelton et al., 2011; Kohl

64 et al., 2016).

66 The role of methane-cycling organisms in serpentinizing systems has been enigmatic since the

67 discovery of thick biofilms of methanogens belonging to order Methanosarcinales in carbonate-

68 brucite chimneys of the Lost City hydrothermal field (Schrenk et al., 2004). Whether these

69 organisms are primarily involved in methane production or methane oxidation remains uncertain

70 (Proskurowski et al., 2008; Bradley, Hayes \& Summons, 2009; Brazelton et al., 2011; Lang et al.,

71 2012; Méhay et al., 2013). Similar methanogens belonging to order Methanosarcinales have been

72 identified in Prony Bay, New Caledonia, where freshwater serpentinizing fluids are venting into

73 shallow marine waters and forming carbonate chimneys on the seafloor (Quéméneur et al., 2014). 
74 16S rRNA genes associated with methanotrophic bacteria have been detected at Lost City

75 (Brazelton et al., 2006) and Prony Bay (Quéméneur et al., 2014).

76

77 Recent studies of non-marine alkaline springs associated with serpentinization have identified

78 16S rRNA and/or methyl coenzyme-M reductase ( $m c r A$ ) genes belonging to methanogens in

79 California (The Cedars: Suzuki et al., 2013; Adobe Springs: (Blank et al., 2009), Costa Rica

80 (Sánchez-Murillo et al., 2014), and the Philippines (Woycheese et al., 2015). At the Tablelands

81 Ophiolite (Newfoundland, CA), however, experimental incubations have been unable to detect

82 methanogenesis at high pH (Morrill et al., 2014), and a metagenomic study at this site did not

83 detect any methanogenesis genes (Brazelton, Nelson \& Schrenk, 2012; Brazelton et al., 2013).

84 16S rRNA and $m c r A$ sequences belonging to the ANME-1a group of anaerobic methanotrophic

85 archaea, but not typical methanogens, were detected in serpentinizing groundwater in the Cabeço

86 de Vide Aquifer in Portugal (Tiago \& Veríssimo, 2013). Biogeochemical studies at The Cedars

87 have inferred biological methanogenesis from isotopic signatures of methane and experimental

88 results, but these studies have not included any biological characterizations of the responsible

89 organisms (Morrill et al., 2013; Wang et al., 2015; Kohl et al., 2016). Thus, methanogens have

90 been detected in some continental serpentinite springs, but previous reports have not provided

91 any quantitative measurements of their environmental distributions nor any genomic or

92 metagenomic sequences from methanogens. Evidence for methanotrophic bacteria in these

93 systems is even more scarce: only a single study of non-marine alkaline springs associated with

94 serpentinization has previously reported methanotrophic bacteria (Sánchez-Murillo et al., 2014). 95 
96 In the Voltri Massif (Italy), ultrabasic springs ( $\mathrm{pH}$ 11-12) rich in calcium and methane are

97 issuing from serpentinites and rare lherzolites and are associated with the precipitation of large

98 amounts of carbonate (Bruni et al., 2002; Cipolli et al., 2004; Boulart et al., 2013;

99 Schwarzenbach et al., 2013). Inorganic carbon geochemistry of the springs and associated

100 travertine deposits suggest autotrophic microbial activity in the subsurface (Schwarzenbach et al.,

101 2013). A previous study has characterized the archaeal and bacterial communities within the

102 travertine deposits formed when the springs reach the surface (Quéméneur et al., 2015), but there

103 are no previous microbiological studies of the spring water. In this report we show that $\mathrm{pH} 12$

104 springs at the Voltri Massif are transporting distinct archaeal and bacterial communities,

105 including methanogenic archaea and methanotrophic bacteria, from subsurface habitats where

106 they are likely to be supported by hydrogen gas, methane, and possibly other products of

107 serpentinization-associated reactions. We provide insights into the biology and potential

108 subsurface habitats of these organisms with metagenomic and experimental studies.

\section{Materials and Methods}

111 Location and sample collection

112 The ultrabasic springs that were investigated in this study (BR2: $44.4512^{\circ} \mathrm{N}, 8.7820^{\circ} \mathrm{E}$; GOR34:

$11344.5970^{\circ} \mathrm{N}, 8.7833^{\circ} \mathrm{E}$ ) are located in the Voltri Massif near Genoa, Italy (Figure 1). Geochemical

114 measurements of these springs were conducted in concert with the microbiological studies

115 reported here and were reported by Schwarzenbach et al. (2013). At each of the BR2 and GOR34

116 locations, ultrabasic spring water and nearby river water were filtered through Millipore Sterivex

$1170.2 \mu \mathrm{m}$ filter cartridges using a portable peristaltic pump. Measurements of $\mathrm{pH}$ and Eh were

118 obtained with an Oakton PCS Testr 35 and an Oakton Testr 10, respectively, from pumped water 
119 that had passed through the peristaltic tubing but before the Sterivex filter (Table 1). Eh readings

120 were corrected for the standard $\mathrm{Ag} / \mathrm{AgCl}$ electrode $(+200 \mathrm{mV})$.

121

122 GOR34-1-spring and GOR34-3-spring (Figure 1A) were sampled from two shallow pools within

123 a large deposit of travertine (Schwarzenbach et al., 2013). Each pool appeared to be fed by a

124 point source of spring water at the bottom, into which peristaltic tubing was inserted as far as

125 possible into the host rock (a few centimeters). The GOR34-1 pool was much smaller than that

126 of GOR34-3, and it was emptied before sampling by siphoning water out of the pool. During

127 pumping and sampling of water from the apparent subsurface source, the pump rate was adjusted

128 to approximately match the rate of inflow, determined by a constant water level in the pool. The

129 volume of water in the GOR34-3 pool did not visibly change during sampling, indicating that the

130 maximum pump rate was significantly slower than the rate of spring water inflow into the pool.

131 The pumped spring water from both GOR34-1 and GOR34-3 became more basic (higher $\mathrm{pH}$ )

132 and more reducing (lower Eh) during pumping of the first few liters, after which the readings

133 stabilized, and filtering commenced. GOR34-river was sampled from the surface of the adjacent

134 river at a site of exposed, rapid flow $\sim 50 \mathrm{~m}$ upstream of the spring.

135

136 BR2-spring was sampled from a metal pipe (Figure 1B) through which spring water was flowing

137 at $492 \mathrm{~mL} \mathrm{~s}^{-1}$ into the adjacent river (Schwarzenbach et al., 2013). After filtering $>500 \mathrm{~L}$ of

138 spring water from BR2-spring in 2012, less than $500 \mathrm{ng}$ of DNA was recovered in initial

139 extractions, which was reduced to $50 \mathrm{ng}$ after pooling and final purification. Even lower yields

140 were achieved in 2013 (Table 2). BR2-river was sampled from the surface of the river at a site of

141 exposed, rapid flow $\sim 10 \mathrm{~m}$ upstream of the spring. 
143 BR2-spring, BR2-river, and GOR34-river were sampled in June 2012 and August 2013.

144 GOR34-1 was sampled in October 2011 and August 2013, while GOR34-3 was only sampled in

145 June 2012. Field replicates were collected for all spring and river samples, but replicates were

146 pooled post-DNA-extraction when necessary to accumulate enough DNA for sequencing.

147 Furthermore, even after pooling of replicates, some samples contained only enough DNA for

148 either 16S rRNA amplicon sequencing or shotgun metagenomic sequencing, but not both. For

149 this reason, BR2-spring-2012, BR2-spring-2013, and GOR34-spring3-2012 are represented in

150 this study by shotgun metagenomic sequences but not 16S rRNA amplicon sequencing surveys

151 (Table 2). When available, field replicates are indicated with 'a' or 'b' at the end of the sample

152 name, such as GOR34-river-2013a and GOR34-river-2013b.

154 Water chemistry

155 Water samples were collected for measurements of hydrogen, methane, sulfate, and sulfide. Gas

156 samples were collected with $100 \mathrm{~mL}$ syringes by sampling $60 \mathrm{~mL}$ of water, minimizing any

157 incorporation of air. Subsequently, $40 \mathrm{~mL}$ of nitrogen or helium gas was introduced to the

158 syringe as headspace gas and the two phases were allowed to equilibrate. The gas phase was

159 injected into evacuated vacutainers for later analysis. The concentrations of gas were determined

160 by gas chromatography (GC), calibrated with commercially available gas standards of known

161 concentration. For hydrogen, samples were injected in split/splitless mode (5:1 split) onto a CP-

162 Molsieve $5 \AA$ column $(50 \mathrm{~m} \times 0.32 \mu \mathrm{m}, 30 \mu \mathrm{m}$ thickness $)$ at $175^{\circ} \mathrm{C}$ with a helium flow rate of 1.8

$163 \mathrm{~mL} / \mathrm{min}$ and detected with a Pulsed Discharge Detector. Methane was determined similarly but

164 with a GS-Carbonplot column $(30 \mathrm{~m} \times 0.32 \mu \mathrm{m}$ ID, $1.5 \mu \mathrm{m}$ film thickness $)$ held at $100^{\circ} \mathrm{C}$ for 3 
165 minutes then ramped at $50{ }^{\circ} \mathrm{C} / \mathrm{min}$ to $200{ }^{\circ} \mathrm{C}$ and held for 0.6 minutes. Detection was with a

166 flame ionization detector. The detection limit was $\sim 0.6 \mathrm{nM}$ for both hydrogen and methane.

167

168 Dissolved inorganic carbon (DIC) measurements were performed on samples that were collected

169 by injecting 1-8 $\mathrm{mL}$ of $0.2 \mu \mathrm{m}$ filtered water into Exetainers (Labco Limited, UK) that had been

170 previously prepared with $\sim 100 \mu \mathrm{L}$ of phosphoric acid and flushed with helium. Concentrations

171 were determined by injecting aliquots of the headspace with a calibrated gas-tight syringe into

172 the same GC set-up used for hydrogen. DIC concentrations from 2011 were reported by

173 Schwarzenbach et al. (2013).

174

175 Sulfide concentrations were determined by the methylene blue method and detected at $610 \mathrm{~nm}$

176 on a spectrophotometer (Cline, 1969). Concentrations were compared to standard curves of

177 freshly prepared sodium sulfide. The detection limit was $3.1 \mu \mathrm{M}$. For sulfate, $100 \mathrm{~mL}$ of water

178 was collected in high density polypropylene bottles and stored cool until analysis.

179 Concentrations were determined by a DX-120 ion chromatograph equipped with an IonPac As14

180 column $(4 \times 250 \mathrm{~mm})$. The detection limit was $1.0 \mu \mathrm{M}$. Organic acids were analyzed by high

181 performance liquid chromatography (HPLC) by the method of Albert \& Martens (1997) with

182 minor modifications. After derivatization with 2-nitrophenyl hydrazine and 1-ethyl-3-(3-

183 dimethylaminopropyl) carbodimide hydrochloride, acids were separated on a Prevail Organic

184 Acid C18 column and detected at $400 \mathrm{~nm}$. Adipic acid was used as an internal standard. 185

186 Enumeration of microbial cells 
187 Fluids (50 mL per field replicate; three replicates per sample in Table 2) were preserved in the

188 field for cell abundance enumeration at a final concentration of $3.7 \%$ formaldehyde and stored at

$1894^{\circ} \mathrm{C}$. In the laboratory, preserved fluids ( 5 to $20 \mathrm{ml}$ each) were filtered through a $0.2 \mu \mathrm{m}$ black

190 polycarbonate filter, and captured cells were stained with DAPI and counted with an

191 epifluorescence microscope. At least 30 fields were counted for each field replicate and used to

192 calculate the average cell concentration per $\mathrm{mL}$ of fluid for that replicate sample. The numbers

193 reported in Table 2 reflect the mean cell concentration for three field replicates from each sample.

DNA extraction and sequencing

197 Filters were placed on ice immediately and stored within a few hours at liquid nitrogen

198 temperature in a vapor shipper (MVE SC4/2V) for frozen transport to the home laboratory. Each

199 Sterivex filter was extracted according to protocols modified from those described in (Huber,

200 Butterfield \& Baross, 2002; Sogin et al., 2006). Briefly, extractions were performed by lysis via

201 freeze/thaw cycles and lysozyme/Proteinase K treatment and purified with phenol-chloroform

202 extractions and precipitation in ethanol. Environmental DNA quantification was performed with

203 the Qubit fluorometer (ThermoFisher). Extraction blanks never yielded quantifiable DNA and

204 were not sequenced. Further purification of DNA was conducted with QiaAmp (Qiagen)

205 columns according to the manufacturer's instructions for purification of genomic DNA. 206

207 Purified DNA was submitted to the Josephine Bay Paul Center, Marine Biological Laboratory 208 (MBL) at Woods Hole for amplicon sequencing of archaeal and bacterial 16S rRNA genes with 209 an Illumina MiSeq platform. The V4-V5 hypervariable region of the bacterial 16S rRNA gene 
210 was targeted with one forward (518F; CCAGCAGCYGCGGTAAN) and three reverse primers

211 (926R; CCGTCAATTCNTTTRAGT; CCGTCAATTTCTTTGAGT;

212 CCGTCTATTCCTTTGANT). The V4-V5 hypervariable region of the archaeal 16S rRNA gene

213 was targeted by a combination of five forward primer variants $(517 \mathrm{~F}$;

214 GCCTAAAGCATCCGTAGC; GCCTAAARCGTYCGTAGC; GTCTAAAGGGTCYGTAGC;

215 GCTTAAAGNGTYCGTAGC; GTCTAAARCGYYCGTAGC) and a single reverse primer

216 (958R; CCGGCGTTGANTCCAATT). Additional methodological details and description of

217 primer development are published in (Nelson et al., 2014; Topçuoğlu et al., 2016). Amplicon

218 sequences were screened for quality, including chimera-checking with UCHIME (Edgar et al.,

219 2011) by the MBL as previously described (Huse et al., 2014a), and high-quality merged

220 sequences were published on the Visualization and Analysis of Microbial Population Structures

221 (VAMPS) website (Huse et al., 2014b).

222

223 The MBL also conducted shotgun metagenomic sequencing of a subset of these samples (see

224 Table 2). Metagenomic libraries were constructed with the Nugen Ultralow Ovation kit

225 according to the manufacturer's instructions. Paired-end sequencing with a 100 cycle Illumina

226 HiSeq run generated partial $\sim 30$ bp overlaps, and six libraries were multiplexed per lane. 16S

227 rRNA amplicon sequences are publicly available at the VAMPS database (http://vamps.mbl.edu)

228 under the project code DCO_BRZ and sample code Serp_LIG. Shotgun metagenomic data is

229 publicly available in MG-RAST under IDs 4545477.3, 4545478.3, 4545479.3, 4545480.3,

$2304537863.3,4537864.3,4537868.3$, and 4537869.3. All sequence data related to this study are

231 also available via the SRA identifier SRP049438 and BioProject PRJNA265986. 
233 Quantitative PCR of archaeal and bacterial 16S rRNA gene copies

234 The 16S rRNA gene copies of Bacteria and Archaea were quantified via quantitative PCR on a

235 BioRad CFX Connect Optics Module with the BioRad SsoAdvanced SybrGreen assay and

236 domain-specific primers targeting the V6 region of the 16S rRNA gene. Primers 958F and

237 1048R were used for Archaea, and primers 967F and 1064R were used for Bacteria (previously

238 published in Sogin et al., 2006 and described on the VAMPS website

239 https://vamps.mbl.edu/resources/primers.php). Gene copy numbers were calculated by plotting

240 quantification values from environmental samples onto standard curves generated by

241 amplification of DNA from Methanocaldococcus jannaschii (for Archaea) and Escherichia coli

242 (for Bacteria) with the domain-specific primers. Bacteria:Archaea ratios were then calculated

243 with gene copy numbers normalized to sample size, i.e. the volume of fluid filtered for that

244 sample.

\section{Analysis of $16 S$ rRNA amplicon data}

247 Additional quality screening of 16S rRNA amplicon sequences from VAMPS was conducted

248 with the mothur (v.1.34.2) software platform (Schloss et al., 2009) to remove sequences with $>9$

249 homopolymers and $>0$ ambiguous bases. This screening step removed only 124 bacterial

250 sequences and 5 archaeal sequences. The sequences were then pre-clustered with the mothur

251 command pre.cluster ( $\operatorname{diffs}=1$ ), which reduced the number of unique sequences from 410,517 to

252322,879 for bacteria and from 138,629 to 95,867 for archaea. This pre-clustering step removes

253 rare sequences most likely created by sequencing errors (Schloss, Gevers \& Westcott, 2011). The

254 final unique sequence types were considered to be the operational taxonomic units (OTUs) for

255 this study. We chose not to cluster sequences any more broadly (e.g. 97\% sequence similarity) 
256 because additional clustering inevitably results in a loss of biological information without

257 reliably improving sequencing error and because no arbitrary sequence similarity threshold can

258 be demonstrated to correspond to consistent species-like units across all taxa. Taxonomic

259 classification of all OTUs was performed with mothur using the SILVA reference alignment

260 (SSURefv119) and taxonomy outline (Pruesse, Peplies \& Glöckner, 2012). Differences in the

261 relative abundances of OTUs between groups of samples were measured with the aid of the R

262 package edgeR v.3.6.8 (Robinson, McCarthy \& Smyth, 2010) as recommended by (McMurdie \&

263 Holmes, 2014). Results were visualized with the aid of the R package phyloseq v.1.9.13

264 (McMurdie \& Holmes, 2013).

265

266 Analysis of metagenomic data

267 Detailed documentation of all computational analyses in this study, including actual software

268 commands, are provided on the Brazelton lab's website (https://baas-

269 becking.biology.utah.edu/data/category/18-protocols), and all custom software and scripts are

270 available at https://github.com/Brazelton-Lab. Quality-filtering of shotgun metagenomic

271 sequences included identification and removal of artifactual sequences with cutadapt v.1.9

272 (Martin, 2011) as follows. Reads found to have Illumina adapters starting at their 5'-end were

273 discarded, and reads containing Illumina adapters towards the 3 '-end were trimmed where the

274 first adapter began. Identical and 5'-prefix replicates were also removed, as suggested by

275 (Gomez-Alvarez, Teal \& Schmidt, 2009). Nucleotides (0-2) at the beginning and end of reads

276 were also cropped from all reads in that sample if those positions exhibited nucleotide

277 frequencies inconsistent with the nucleotide frequency distribution for the rest of the read. Low-

278 quality bases were removed from the ends of the reads, and the remaining sequence was scanned 
27920 base pairs at a time and trimmed where the mean quality score fell below a score of 8 . Reads

280 that did not pass a minimum length threshold of $62 \mathrm{bp}$ after quality and adapter trimming were

281 removed from the dataset. Phylogenetic affiliations of the unassembled, quality-checked paired

282 reads were determined with PhyloSift v.1.0.1 (Darling et al., 2014).

283

284 Each metagenomic dataset was processed individually as described above. The four

285 metagenomes from ultrabasic springs and the four metagenomes from adjacent rivers were then

286 combined for two pooled assemblies with Ray Meta v.2.3.1 (Boisvert et al., 2012). A kmer of 41

287 was chosen after manual inspection of assemblies with kmer values of $31,41,51$, and 61 . High-

288 quality reads from each sample were mapped onto the pooled assembly with Bowtie2 v.2.2.6

289 (Langmead \& Salzberg, 2012) to obtain sample-specific coverages. The Prokka pipeline

290 (Seemann, 2014) was used for gene prediction and functional annotation. The arguments --

291 metagenome and --proteins were used with Prokka v.1.12 to indicate that genes should be

292 predicted with the implementation of Prodigal v.2.6.2 (Hyatt et al., 2010) optimized for

293 metagenomes and then searched preferentially against a custom protein database. The database

294 provided was the Kyoto Encyclopedia of Genes and Genomes FTP release 2016-09-26 (Ogata et

295 al., 1999). Abundances of metabolic pathways were obtained by mapping KEGG protein IDs and

296 their normalized counts calculated with HTSeq v.0.6.1 (Anders, Pyl \& Huber, 2015) onto the

297 FOAM ontology (Prestat et al., 2014) with MinPath (Ye \& Doak, 2009) as implemented in

298 HUMAnN2 v.0.6.0 (Abubucker et al., 2012). Similar results were also achieved by annotating

299 both pooled assemblies with the UniProtKB protein database (Consortium, 2015) and MetaCyc

300 pathways (Caspi et al., 2014). 
302 Contigs from the pooled spring assembly were binned according to their tetranucleotide

303 frequencies with the aid of an emergent self-organized map (ESOM) as implemented by

304 Databionic ESOM tools v.1.1 (Ultsch \& Mörchen, 2005) and as described by (Dick et al., 2009).

305 The resulting ESOM was annotated with phylogenetic markers classified by PhyloSift and

306 selected predicted protein functions of interest identified by KEGG ID. Completeness and

307 contamination of ESOM bins were evaluated with CheckM v.1.0.4 (Parks et al., 2015).

308 Contamination levels as measured by CheckM do not always agree with the percentage of

309 minority taxa reported by PhyloSift because CheckM only identifies contamination when single-

310 copy markers are present as multiple, divergent sequences and because PhyloSift results are

311 abundance-weighted.

312

313 Metabolic Activity Assays

314 During each sampling expedition, water samples collected from each of the BR2 and GOR34

315 springs were incubated with one of several ${ }^{13} \mathrm{C}$-labeled carbon sources (obtained from

316 Cambridge Isotope Laboratories, Tewksbury, MA): bicarbonate $\left(\mathrm{NaH}^{13} \mathrm{CO}_{3}\right)$, formate

$317\left(\mathrm{Na}^{13} \mathrm{CHOO}\right)$, acetate- ${ }^{13} \mathrm{C} 1\left(\mathrm{NaCH}_{3}{ }^{13} \mathrm{COO}\right)$, acetate- ${ }^{13} \mathrm{C} 2\left(\mathrm{Na}^{13} \mathrm{CH}_{3} \mathrm{COO}\right)$, propionate

$318\left(\mathrm{NaCH}_{3} \mathrm{CH}_{2}{ }^{13} \mathrm{COO}\right)$, or methane $\left({ }^{13} \mathrm{CH}_{4}\right)$. Each $99 \%{ }^{13} \mathrm{C}$-labeled carbon compound was diluted

319 1:100 with the corresponding non- ${ }^{13} \mathrm{C}$-labeled compound to produce a final $\delta^{13} \mathrm{C}$ of $+691 \%$, and

320 this compound was present in each incubation at a final concentration of $0.1 \mathrm{M}$ after addition of

$3213 \mathrm{~mL}$ of water sample. No buffering nor additional amendments were applied to the incubations,

322 and the experiments are assumed to have proceeded at the in situ $\mathrm{pH}$ of the spring water. 'Dead'

323 control incubations were conducted by filter-sterilizing the spring water through a $0.2 \mu \mathrm{m}$

324 syringe filter in the field and prior to incubation. Three live replicates and three dead replicates 
325 from each spring were incubated for each treatment. Methanogenesis experiments received an

326 addition of $5 \mathrm{cc} \mathrm{H}_{2}$ gas to each replicate. Methanotrophy experiments received an addition of 5

$327 \mathrm{cc}^{13} \mathrm{CH}_{4}$ that had been diluted 1:10 with non- ${ }^{13} \mathrm{C}$-labeled methane. All incubations were

328 conducted in gas-tight glass Exetainers (Labco Limited, UK) flushed with $\mathrm{N}_{2}$ and 2-5\% $\mathrm{H}_{2}$ in a

329 Coy anoxic chamber and flushed again outside the chamber and slightly over-pressured for

330 transport with $\mathrm{N}_{2}$ gas. Oxic methanotrophy experiments were conducted after exposing the

331 contents to room air by opening the lids for a few minutes prior to adding ${ }^{13} \mathrm{CH}_{4}$. Some

332 methanogenesis experiments were treated with a reducing agent in the form of $0.3 \mathrm{~mL}$ of $1 \%$

333 dithiothreitol (DTT) or 2.5\% sodium sulfide, but no differences were observed with or without

334 the additional reducing agent. After incubation at ambient temperature $\left(20-35^{\circ} \mathrm{C}\right)$ in the dark for

335 4-8 days, Exetainers were injected with $0.2 \mathrm{~mL}$ of $50 \%$ phosphoric acid to convert all dissolved

336 inorganic carbon into $\mathrm{CO}_{2}$, and the ${ }^{13} \mathrm{C} /{ }^{12} \mathrm{C}$ ratios of $\mathrm{CO}_{2}$ and $\mathrm{CH}_{4}$ were measured by gas

337 chromatography isotope ratio mass spectrometry using a Thermo Fisher Delta V Plus Isotope

338 Ratio Mass Spectrometer, interfaced with a Trace gas chromatograph, a GC IsoLink interface

339 and a ConFlo IV at the Stable Isotope Laboratory of the ETH in Zurich.

\section{Results}

342 Biogeochemical contrasts between ultrabasic springs and surface rivers

343 At both the BR2 and GOR34 sites, the spring water had much higher $\mathrm{pH}$, lower Eh (i.e. more

344 reducing), fewer particulates, and lower biomass than the adjacent river (Tables 1-2). The high

$345 \mathrm{pH}$ (up to 12.3) and low Eh are consistent with the spring water being sourced from ultramafic

346 rocks where serpentinization-like reactions are occurring now or have occurred in the past (Alt et

347 al., 2013). The difference in particulates was noticeable due to the much greater volumes of 
348 spring water, compared to surface river water, that could be filtered through a single Sterivex

349 cartridge before clogging (more than 20-50 L for springs, only 2-5 L for surface rivers). The

350 difference in biomass was also evident from the DNA yield: the GOR34 springs yielded 3-5-fold

351 less DNA per liter of water compared to the adjacent river, and the BR2 spring yielded >1,000-

352 fold less DNA per liter of water compared to the adjacent river. The cell densities (as measured

353 by enumeration of DAPI-stained cells under a microscope $)$ of the BR2 spring $\left(10^{2}-10^{3}\right.$ cells per

$354 \mathrm{~mL}$ of water) were 2-40-fold lower than the cell densities of the adjacent river (Table 2). The cell

355 densities of the GOR34 springs were 2-20-fold lower than the adjacent river.

356

357 BR2 spring waters contained higher methane and lower hydrogen concentrations compared to

358 the GOR34 springs (Table 1). At both sites, spring water contained much lower dissolved

359 inorganic carbon (DIC) than in the adjacent rivers, likely due to the precipitation of calcium

360 carbonate at high pH (Schwarzenbach et al., 2013; Alt et al., 2013). Sulfate was also very low in

361 all springs, though detectable at BR2. Sulfide was elevated in all springs compared to the

362 adjacent rivers.

363

364 Taxonomic survey of bacterial 16S rRNA genes

365 The bacterial taxonomic composition of the $\mathrm{pH} 12$ spring GOR34-spring1 was distinct from that

366 of surface rivers, as measured by high-coverage Illumina MiSeq sequencing of bacterial 16S

367 rRNA gene amplicons. Comamonadaceae (a member of order Burkholderiales, class

368 Betaproteobacteria) was the most abundant family in GOR34-spring1 in 2013 (35-40\% of all

369 bacterial 16S rRNA amplicon sequences, Supplementary File S1). The most abundant OTU

370 within this family is $100 \%$ identical to the most abundant OTU recovered from ultrabasic 
371 serpentinite springs at the Tablelands Ophiolite in Newfoundland, Canada (Brazelton et al., 2013)

372 and to the most abundant OTU in borehole fluids from the Coast Range Ophiolite Microbial

373 Observatory in California (Crespo-Medina et al., 2014). This same bacterial taxon has been

374 isolated from serpentinite springs at The Cedars (northern California) by Suzuki et al. (2014),

375 who have proposed the novel genus Serpentinomonas for these organisms. Curiously,

376 Comamonadaceae sequences only comprised $14 \%$ of all bacterial sequences in GOR34-spring1

377 in 2011. Instead, the most abundant sequences were those classified as Candidate Division OD1

378 (21\% of sequences in GOR34-spring1 in 2011 but only 4\% in 2013).

379

380 Comamonadaceae sequences were also well represented in surface river samples (Supplementary

381 File S1), but the Comamonadaceae OTUs from river samples were distinct from the

382 Comamonadaceae OTUs from ultrabasic spring samples (only 94\% sequence identity over 373

383 bases between the most abundant Comamonadaceae OTU in GOR34-spring1-2013b compared to

384 the most abundant Comamonadaceae OTU in GOR34-river-2013). Neither of these sequences

385 could be classified at a lower taxonomic rank than family. This result highlighted the need to

386 conduct comparisons of bacterial community compositions at the level of individual OTUs

387 (Supplementary File S2), rather than taxonomic classifications.

Differential abundance of bacteria

390 Although the bacterial community compositions of ultrabasic springs and the adjacent rivers

391 were generally distinct, the most abundant OTUs in rivers were also present, at low relative

392 abundances, in ultrabasic springs, and the converse was also true. In other words, the most

393 abundant 16S rRNA OTUs at each site were not completely exclusive to that site. For example, 
394 the most abundant OTU in GOR34-river-2013b (classified as Sphingomonadaceae) occurred

3958515 times in that sample and 0 and 4 times in GOR34-spring1-2013a and GOR34-spring1-

396 2013b, respectively. Conversely, the most abundant OTU in GOR34-spring1-2013b (the

397 Comamonadaceae Serpentinomonas OTU described above) occurred 32,866 times in that sample

398 and 71 and 0 times in GOR34-river-2013a and GOR34-river-2013b, respectively

399 (Supplementary File S2). As with any environmental study, these sequences could have appeared

400 in multiple locations because of natural mixing in the environment or due to accidental

401 contamination during sampling or sequencing. Regardless of the cause, the source of shared

402 sequences can be inferred by making the parsimonious assumption that the site of higher

403 abundance is closer to that organism's true habitat. Therefore, we looked for potential

404 subsurface-specific organisms by testing for significant differences in the abundances of

405 individual OTUs between ultrabasic spring water and the adjacent river.

406

407 For this analysis, we contrasted the counts of OTUs in GOR34-spring1 to those in GOR34-river.

408 Each site was represented by two field replicates collected in 2013 (Table 2). In Figure 2, each

409 data point of the plot represents the difference in abundance of a single OTU between GOR34-

410 spring1 and GOR34-river. The plot's $\mathrm{x}$-axis displays the mean abundance (in units of $\log _{2}$ counts

411 per million) of each OTU across all four samples (two GOR34-spring1 replicates and two

412 GOR34-river replicates). Red data points indicate OTUs whose differential abundance between

413 GOR34-spring1 and GOR34-river passed a significance test (false discovery rate $<0.05$ )

414 implemented by the edgeR package (Robinson, McCarthy \& Smyth, 2010). Spring-enriched

415 OTUs include the Comamonadaceae described above as well as a group of uncultured

416 Bacteroidetes known as aquatic group ML635J-40, Candidate Division OD1, an uncultured 
417 group within the Thermoanaerobacterales, and Methylococcaceae (Figure 2A). Sequences that

418 were not consistently enriched in one sample type compared to the other are represented by black

419 points in Figure 2. These sequences could represent potential contaminants or truly cosmopolitan

420 species, or their abundances may be correlated to factors not captured by the study design. The

421 data visualization approach in Figure 2 highlights the key differences between the spring and

422 river microbial communities by acknowledging the reality that all environmental samples are

423 mixtures formed by multiple sources of organisms and without making the naive and extreme

424 assumption that all shared sequences must be some kind of contamination.

425

426 Taxonomic survey of archaeal $16 S$ rRNA genes

427 As with the bacterial communities, the archaeal communities in the ultrabasic spring waters were 428 distinct from those in the surface rivers, as measured by high-coverage Illumina MiSeq

429 sequencing of archaeal $16 \mathrm{~S}$ rRNA gene amplicons. More than $88 \%$ of total archaeal sequences in

430 GOR34-spring1-2013, for example, belong to the Methanobacteriaceae family of methanogens.

431 The closest match ( $97 \%$ sequence similarity) in the GenBank, VAMPS, and SILVA databases

432 to these Methanobacteriaceae sequences is a clone from subsurface water collected in a deep

433 South Africa mine (GenBank DQ230925). The taxonomic composition of GOR34-river was

434 nearly completely different; $72 \%$ of sequences in both 2012 and 2013 were assigned to Marine

435 Group I, within the Thaumarchaeota (Supplementary File S3). As with the bacterial sequences,

436 the most abundant archaeal OTUs in GOR34-river were also present, at low relative abundances,

437 in GOR34-spring1, and the converse was also true. For example, the most abundant OTU in

438 GOR34-spring1-2013b occurs 89,407 times in that sample, 127 times in GOR34-river-2013, and 43924 times in GOR34-river-2012 (Supplementary File S4). 
441 We identified potential subsurface-specific archaeal 16S rRNA OTUs by contrasting the archaeal

442 sequences from GOR34-spring1 to those of GOR34-river. Unfortunately, GOR34-spring1-2013b

443 was the only spring sample to yield sufficient DNA and sufficient read coverage for this analysis

444 of archaeal 16S rRNA sequences. GOR34-river is represented in this analysis by two samples:

445 GOR34-river-2012a and GOR34-river-2013a. Not surprisingly, considering the differential

446 abundances reported above, the Methanobacteriaceae sequences were identified as the most

447 abundant OTUs that were significantly enriched in GOR34-spring1 (Figure 2B). Other families

448 of methanogens in addition to Methanobacteriaceae were identified in the 16S rRNA sequences,

449 but none were significantly more abundant in the ultrabasic springs compared to the adjacent

450 river. One sequence belonging to family Methanosaetaceae (order Methanosarcinales) was

451 enriched in the GOR34 spring compared to the adjacent river in 2013, but Methanosaetaceae

452 sequences were equally abundant in the river in 2012 (Supplementary Files S3-S4). The only

453 OTUs that could be considered significantly enriched in GOR34-river belong to the

454 Thaumarchaeota Marine Group I family. The variability of less abundant OTUs between the two

455 samples from GOR34-river prevented them from passing our significance test, even though

456 many of them were extremely rare or absent in GOR34-spring1.

457

458 Taxonomic survey of shotgun metagenomic sequences

459 Phylogenetic classifications (from PhyloSift) of unassembled metagenomic sequences were

460 largely consistent with the 16S rRNA amplicon results described above. For example, even

461 though Comamonadaceae was the most common family identified in metagenomic sequences

462 from the ultrabasic springs as well as the river at GOR34 (Supplementary File S5), the sample 
463 types differed at the genus level: Hydrogenophaga was the most common member of

464 Comamonadaceae in the GOR34-spring1 and GOR34-spring3 metagenomes, whereas

465 Acidovorax was the predominant representative of Comamonadaceae in GOR34-river

466 (Supplementary File S6). Comamonadaceae sequences were also abundant in metagenomic data

467 from the ultrabasic spring at BR2, although this site appears to be dominated by

468 Desulfovibrionales, a member of Deltaproteobacteria (Supplementary File S5).

469

470 Metagenomic sequences predicted to represent methanogens (family Methanobacteriaceae)

471 comprised $\sim 1 \%$ of shotgun sequences in BR2-spring-2012 and GOR34-spring3-2012

472 (Supplementary File S5). Curiously, no methanogen sequences were found in GOR34-spring1-

$4732013 b$ (Supplementary File S6), despite their dominance in the archaeal 16S rRNA amplicon

474 data from this same sample (Figure 2). None of the 28 million sequence pairs in this

475 metagenome were classified as domain Archaea, so it is possible that the ratio of bacterial to

476 archaeal DNA in this sample was very high. A quantitative PCR assay of bacterial and archaeal

477 16S rRNA gene copies indicated a 10:1 ratio of Bacteria:Archaea (Table 2) in GOR34-spring1-

478 2013b, which would predict a minority, but perhaps not a complete absence, of archaeal

479 sequences in its metagenome. The Bacteria:Archaea ratio for BR2-spring-2012 was less than 2:1,

480 and only $3 \%$ of shotgun metagenomic sequences from this sample were classified as Archaea,

481 indicating a lack of direct correspondence between quantitative PCR results and numbers of

482 shotgun sequences. When archaea were detected in metagenomic sequences from the rivers

483 adjacent to the BR2 and GOR34 springs, they were dominated by Thaumarchaeota

484 (Supplementary File S5), consistent with the archaeal 16S rRNA amplicon results (Figure 2). No

485 Methanobacteriaceae sequences were detected in the metagenomic data from either river. 
487 Metagenomic assembly and metabolic pathway prediction

488 Shotgun metagenomic sequences were assembled into contiguous genomic fragments (contigs),

489 which were used for predictions of genes, protein functions, and metabolic pathways. Because

490 the four metagenomes from ultrabasic springs (BR2-spring-2012, BR2-spring-2013, GOR34-

491 spring1-2013b, and GOR34-spring3-2012) were similar to each other in taxonomic composition

492 (Supplementary Files S5-S6), they were combined in a pooled assembly called 'combined-

493 spring'. The N50 (length of median contig) of this pooled assembly was $2.4 \mathrm{~kb}$ (Table 3 ), and the

494 longest contig was $99 \mathrm{~kb}$. Of the 104,651 predicted proteins in the combined-spring assembly,

49549,794 could be annotated with the KEGG database. A large proportion (45\%) of predicted

496 proteins had no matches in any of the protein databases and could not be assigned a function

497 (Table 3). The four metagenomes from adjacent rivers (BR2-river-2012a, BR2-river-2013,

498 GOR34-river-2012a, and GOR34-river-2013b) were also combined for a pooled assembly called

499 'combined-river', which has similar assembly statistics to the combined-spring assembly (Table $500 \quad 3$ ).

501

502 The abundance of metabolic pathways was determined by mapping predicted protein functions

503 (as annotated with KEGG) and their sequencing read coverages onto the FOAM ontology. Many

504 of the most abundant predicted pathways in the ultrabasic springs involved transporters and

505 stress responses, possibly indicating cellular responses to the extreme environmental conditions.

506 The most abundant energy-conserving metabolic pathways included those involved in

507 fermentation, methanogenesis, sulfur oxidation, denitrification, methylotrophy, and hydrogen

508 oxidation and production (Supplementary File S7). The presence of genes associated with the 
509 aerobic oxidation of hydrogen and methanogenesis are are expected from the dominance of the

510 Hydrogenophaga and Methanobacteriaceae sequences described above. The abundance of

511 several pathways involved in fermentation and hydrogen production is consistent with the

512 presence of Clostridiaceae and Bacteroidetes, and the detection of methylotrophy pathways is

513 consistent with the presence of Methylococcaceae in the ultrabasic springs (Supplementary File

514 S7).

515

516 Methanogenesis pathways using carbon dioxide and formate were among the most abundant

517 pathways in the spring metagenomes, but other FOAM-defined methanogenesis pathways

518 predicted to utilize acetate and methylated compounds were also predicted to be present in these

519 springs (Supplementary File S7). To better understand the evidence for different kinds of

520 methanogenesis pathways in these springs, we examined the presence of each key

521 methanogenesis-associated gene. All of the steps in the 'core' methanogenesis pathway were

522 represented by at least one predicted protein (as defined by KEGG) in the combined-spring

523 assembly (green highlighting in Figure 3). The only exception is the lack of sequences encoding

524 the enzyme $\mathrm{Hmd}\left(\mathrm{H}_{2}\right.$-forming methylenetetrahydromethanopterin dehydrogenase), but this gene

525 is not present in many methanogens (Fricke et al., 2006), including the five Methanobacterium

526 genomes currently available in the Integrated Microbial Genomes database (img.jgi.doe.gov).

528 All of the genes encoding formate dehydrogenase (Fdh), acetate kinase (Ack),

529 phosphotransacetylase (Pta), AMP-forming acetyl-CoA synthetase (Acs), and carbon monoxide

530 dehydrogenase / acetyl-CoA decarbonylase/synthase (Cdh/ACDS) are present in the combined-

531 spring assembly. The presence of these genes indicates the genetic potential for both formate and 
532 acetate to be used as substrates for methanogenesis, although these proteins can be utilized by

533 non-methanogens as well, which can explain why some of these proteins are also found in the

534 combined-river assembly (yellow highlighting in Figure 3). Two of the three genes encoding Mta

535 (methanol-specific methylcobalamin:coenzyme M methyltransferase) are also present,

536 suggesting methanol as another potential substrate for methanogenesis.

Binning of metagenomic assembly

539 In order to examine the distribution of predicted protein functions and metabolic pathways

540 among putative organisms within the combined-spring assembly, fragments of metagenomic

541 contigs were binned according to their tetranucleotide compositions with an emergent self-

542 organizing map (ESOM). Each point in the ESOM in Figure 4 represents a contig or a $\sim 5 \mathrm{~kb}$

543 fragment of a contig if the original contig was larger than $5 \mathrm{~kb}$. In Figure 4A, contigs containing

544 PhyloSift taxonomic markers that correspond to the enriched taxa in Figure 2 are colored

545 accordingly. Figure 4B is the same map as Figure 4A, but in this case, fragments are color-coded

546 according to the presence of predicted proteins associated with metabolic functions of interest

547 (Supplementary File S8). Five bins of metagenomic fragments with relatively homogenous

548 taxonomic assignments were identified in this ESOM (Table 4). Unfortunately, none of the five

549 bins contained any 16S rRNA genes, so direct links to the 16S rRNA gene amplicon data could

550 not be made, and comparisons with PhyloSift taxonomic classifications of protein-encoding

551 taxonomic markers are reported below instead.

552

553 ESOM Bin 1 (44\% complete, 1\% contamination) corresponds to the Methanobacteriaceae 16S

554 rRNA sequences that were enriched in the ultrabasic springs (Figure 2) because $88 \%$ of its 
555 sequences encoding taxonomic markers were classified as Methanobacteriaceae by PhyloSift

556 (Supplementary File S6). Furthermore, genomes belonging to genus Methanobacterium were the

557 most common source of best hits when sequences belonging to ESOM Bin 1 were competitively

558 recruited to a set of all methanogen genomes available from GenBank. ESOM Bin 1 sequences

559 were recruited to many other types of methanogens as well, indicating that this bin does not have

560 a single nearly identical whole-genome match in GenBank. ESOM Bin 1 includes many of the

561 methanogenesis-associated sequences in the combined-spring assembly (black borders in Figure

562 3), including genes involved in the utilization of formate, acetate, and methanol as substrates for

563 methanogenesis. Two of the genes encoding nitrogenase (nifDK) were also identified in this bin,

564 suggesting the potential for nitrogen fixation (Supplementary File S8), which is consistent with

565 the low levels of fixed nitrogen expected to be in the spring water (Cipolli et al., 2004).

566 Curiously, ESOM Bin 1 does not include any of the genes that encode formylmethanofuran

567 dehydrogenase, which catalyzes the first step of methanogenesis when carbon dioxide is the

568 carbon source (Figure 3). Although the absence of genes in an incomplete metagenomic bin

569 cannot be definitive, it is nevertheless interesting to observe that the only methanogens known to

570 lack all of the formylmethanofuran dehydrogenase genes (according to a comparison of KEGG

571 annotations on JGI's Integrated Microbial Genomes website) are members of genus

572 Methanomasssiliicoccus, which use methanol as their carbon source and cannot grow on carbon 573 dioxide.

575 ESOM Bin 2 (42\% complete, $12 \%$ contamination) includes sequences that were classified as

576 Comamonadaceae ( $43 \%$ of taxonomic markers) and Xanthomonadaceae (27\% of taxonomic

577 markers) (Supplementary File S6). Both of these bacterial families were also among the most 
578 abundant taxa identified in the bacterial 16S rRNA data (Figure 2). Repeated attempts to

579 partition this bin to separate the Comamonadaceae and Xanthomonadaceae sequences were

580 unsuccessful, suggesting shared sequence compositions and/or mis-assembly. ESOM Bin 2

581 encodes RuBisCo (ribulose-1,5-bisphosphate carboxylase/oxygenase), the key enzyme in the

582 Calvin-Benson-Bassham pathway of carbon fixation. The predicted protein sequence of the large

583 subunit has $83 \%$ identities and $91 \%$ similarities with the Comamonadaceae RuBisCo sequence

584 identified in metagenomic sequences from a serpentinite-hosted ultrabasic spring at the

585 Tablelands Ophiolite in Newfoundland, Canada (Brazelton, Nelson \& Schrenk, 2012). Nearly all

586 predicted proteins in the combined-spring assembly involved in the degradation of chlorinated

587 aromatic compounds are also found in ESOM Bin 2 (Supplementary File S7), and these

588 sequences have close matches in other Comamonadaceae genomes. This bin does not include

589 any sequences encoding a NiFe-hydrogenase, but there is at least one large contig in the

590 combined-spring assembly that encodes a $\mathrm{NiFe}$-hydrogenase with $84 \%$ amino acid identities

591 with the group $1 \mathrm{NiFe-hydrogenase} \mathrm{from} \mathrm{Serpentinomonas} \mathrm{strain} \mathrm{H1,} \mathrm{a} \mathrm{Comamonadaceae} \mathrm{isolate}$

592 from a serpentinite spring at The Cedars, California (Suzuki et al., 2014).

593

594 ESOM Bin 3 (28\% complete, $2 \%$ contamination) is a collection of sequences with PhyloSift

595 classifications consistent with that of the Bacteroidetes uncultured aquatic group 'ML635J-40',

596 which was identified as the second-most abundant bacterial taxon in the ultrabasic springs

597 (Figure 2). 92\% of all taxonomic markers in ESOM Bin 3 were classified as Bacteroidetes

598 (Supplementary File S6), although these sequences were somewhat evenly distributed among

599 several different families within the Bacteroidetes, consistent with the undetermined

600 phylogenetic placement of the ML635J-40 aquatic group (Nolla-Ardèvol, Strous \& Tegetmeyer, 
601 2015). This bin includes 50\% of all combined-spring metagenomic sequences assigned to the

602 FOAM pathway 'Pyruvate fermentation to acetate III' and is also rich in sugar transporters

603 (Supplementary File S7). ESOM Bin 3 encodes multiple [FeFe]-hydrogenases with high

604 similarity to those encoded by other Bacteroidetes including Lentimicrobium saccharophilum

605 (GenBank GAP44922.1) and Alistipes sp. ZOR0009 (GenBank WP_047449271).

606

607 ESOM Bin 4 (48\% complete, 6\% contamination) corresponds to the Methylococcaceae $16 \mathrm{~S}$

608 rRNA sequences identified in Figure 2. $60 \%$ of taxonomic markers in this bin were classified as

609 family Methylococcaceae, and 82\% were classified as order Methylococcales (Supplementary

610 File S6). Bacteroidetes sequences comprised 12\% of taxonomic markers in this bin. Predicted

611 protein sequences for particulate and soluble methane monooxygenase (pmoCAB, K10944-46;

612 mmoXYBZDC, K16157-16162) were prominent in ESOM Bin 4 (Supplementary File S8), and

613 they shared 83-90\% amino acid identities with sequences from Methylobacter and

614 Methylomicrobium species. The most abundant Methylococcaceae 16S rRNA gene amplicon

615 sequences in the ultrabasic springs are most similar to a clone recovered from a deep mine in

616 South Africa (Blanco et al., 2014), which is most closely related to Methylosoma difficile

617 (Rahalkar, Bussmann \& Schink, 2007).

618

619 ESOM Bin 5 (60\% complete, 6\% contamination) appears to capture much of the genomic

620 content associated with the Desulfovibrionales 16S rRNA sequences that dominate the BR2-

621 spring-2012 metagenome. 83\% of taxonomic markers in this bin were classified as

622 Desulfovibrionales (Supplementary File S6). Furthermore, [NiFe]-hydrogenase sequences in

623 ESOM Bin 5 have high similarity to other Desulfobivrionales genomes; for example, one 
624 predicted protein sequence has $90 \%$ identity with the hydrogenase 2 large subunit of

625 Desulfonatronum lacustre (Pikuta et al., 2003). The Desulfonatronum genus includes several

626 alkaliphilic, hydrogen-oxidizing species, although there are no reports of Desulfonatronum

627 growth above $\mathrm{pH}$ 10. In addition to [NiFe]-hydrogenase (hydAB; K18008, K00437), most of the

628 combined-spring metagenomic sequence coverage of carbon monoxide dehydrogenase (cooS;

629 K00198), acetyl-coA synthase (acsB; K14128), three subunits of acetyl-CoA

630 decarbonylase/synthase complex (Cdh/ACDS; K00194, K00197, K00198), dissimilatory sulfite

631 reductase (dsrAB; K11180-81), heterodisulfide reductase ( $h d r A B C ; \mathrm{K} 03388-\mathrm{K} 03390$ ), and

632 phosphate transacetylase ( $p t a ; \mathrm{K} 13788$ ) were included in this bin (Supplementary File S8).

633

634 Metabolic activity assays

635 The activity of methanogenesis, methanotrophy, and oxidation of organic acids in ultrabasic

636 springs was tested by measuring the conversion of ${ }^{13} \mathrm{C}$-labeled carbon compounds during

637 incubations of spring water samples at ambient temperatures $\left(\sim 20-25^{\circ} \mathrm{C}\right)$ in the dark. A single

638 plus symbol in Table 5 indicates that the ${ }^{13} \mathrm{C}$ ratio of the product for that reaction was higher in

639 all three live replicates compared to all three dead replicates, which had been filter-sterilized

640 prior to incubation. Double plus symbols indicate that the live replicates were 10-60\%o heavier

641 than the corresponding dead replicates, and triple plus symbols indicate that the live replicates

642 were $100-700 \%$ heavier than the dead replicates.

643

644 Methanogenesis from acetate was detected in GOR34-spring3-2011. Unfortunately, insufficient 645 material was collected from this spring in 2011 for high-quality sequencing studies, and

646 subsequent metabolic activity experiments failed to detect methane production, most likely due 
647 to technical difficulties with performing these experiments. Curiously, methane production was

648 only detected from the carboxyl group ( $\mathrm{C} 1$ atom) of acetate. Acetoclastic methanogenesis

649 generates methane by reduction of the methyl group (C2 atom), so this result suggests that the

650 carboxyl group of acetate was first oxidized to inorganic carbon (carbon dioxide, bicarbonate, or

651 carbonate) and then utilized by methanogens. Indeed, oxidation of acetate to carbon dioxide was

652 observed in GOR34-spring3-2011. Methane oxidation to carbon dioxide was also observed at

653 least once in all three springs. Methane oxidation signals were greatly increased when

654 incubations were exposed to oxygen (indicated by the third plus symbol in GOR34-spring 1-2012

655 in Table 5) and were completely eliminated by addition of a reducing agent. This result strongly

656 indicates that the measured methane oxidation was aerobic, although some activity was also

657 detected even without oxygen exposure.

658

659 Discussion

660 Methanogenesis

661 This study of ultrabasic springs at the Voltri Massif provides the first metagenomic evidence for

662 methanogens and methanogenesis pathways in a continental serpentinizing system. All genes

663 required for methanogenesis are present in the combined-spring assembly (Figure 3), and many

664 of these were collected in a single metagenomic bin corresponding to the Methanobacteriaceae

665 taxa that are enriched in the ultrabasic springs (Figure 2). The combined-spring assembly

666 includes the genetic potential for the utilization of carbon dioxide, formate, acetate, and methanol

667 as methanogenic substrates. Some of the genes involved in carbon dioxide, formate, and acetate

668 utilization were also found in genomic bins for non-methanogens and in the adjacent rivers, but

669 the two proteins required for the utilization of methanol as a methanogenic substrate were unique 
670 to the Methanobacteriaceae bin. Furthermore, the Methanobacteriaceae bin lacked all known

671 genes for the utilization of carbon dioxide for methanogenesis. There are no previous examples

672 of organisms within family Methanobacteriaceae that can use methanol as a substrate, so this

673 result should be confirmed with additional genomic and experimental data. Nevertheless,

674 methanol and formate are among the single carbon compounds predicted to be abiogenic

675 products of serpentinization (Shock, 1992; Shock \& Schulte, 1998; Seewald, Zolotov \&

676 McCollom, 2006), so these metagenomic data are consistent with the possibility that

677 Methanobacteriaceae methanogens at this site are directly supported by subsurface

678 serpentinization reactions.

679

680 We detected active methanogenesis in GOR34-spring3 (Table 5), which is assumed to have

681 occurred at close to the in situ $\mathrm{pH}$ of the spring (pH 11.8). To our knowledge, this would

682 represent the highest $\mathrm{pH}$ known to support methanogenesis, although no $\mathrm{pH}$ measurements were

683 made during or after the incubation experiments. Methane produced during this experiment was

684 derived from the carboxyl group ( $\mathrm{C} 1$ atom) of acetate, and no methane was produced from the

685 methyl group (C2 atom). This is contrary to the expectation for acetate-based methanogenesis,

686 which produces methane by reduction of the methyl group. Furthermore, Methanobacteriaceae

687 methanogens are not known to be able to use acetate as a substrate for methanogenesis.

688 Therefore, it is more likely that the carboxyl group was oxidized to inorganic carbon (activity for

689 which was also detected in this spring; see Table 5) and subsequently utilized for

690 methanogenesis directly or indirectly. Unfortunately, methanogenesis from inorganic carbon

691 (carbon dioxide, bicarbonate, or carbonate) was not measured during that experiment, and

692 subsequent experiments failed to detect methanogenesis from any substrates. These results are 
693 also not easily reconciled with the absence of genes required for the utilization of carbon dioxide

694 for methanogenesis in the Methanobacteriaceae ESOM bin. Thus, the genomic evidence for the

695 potential of formate, acetate, and methanol to support methanogenesis by Methanobacteriaceae

696 organisms remains only incompletely confirmed by metabolic activity experiments. Future

697 experimental studies designed to test the utilization of specific carbon compounds during active

698 methanogenesis at high $\mathrm{pH}$ would provide stronger evidence for the link between subsurface

699 carbon sources and methanogens in serpentinite springs.

700

701 Methanobacteriaceae (as well as orders Methanosarcinales and Methanocellales) have been

702 previously detected in travertine deposits formed by ultrabasic springs of the Voltri Massif

703 nearby, but not the same as, the springs described here (Quéméneur et al., 2015). The presence of

704 Methanobacteriaceae in the carbonate deposits raises the question of whether they primarily

705 inhabit surface or subsurface environments. Methanobacteriaceae and predicted proteins in the

706 methanogenesis pathway are abundant in the BR2 spring (Supplementary Files S5-S8), which is

707 not submerged by an overlying pool, does not appear to come into contact with surface travertine

708 deposits, and can be sampled directly from the spring's source (Figure 1). Therefore, the high

709 abundance of Methanobacteriaceae in this spring suggests a subsurface habitat for these

710 methanogens, although it is possible that these organisms could be active in both subsurface

711 springs and surface deposits where biofilms may create anoxic micro-environments.

712

713 Hydrogen metabolism

714 In addition to hydrogen gas consumption by methanogens, the Voltri Massif springs encode

715 abundant genes for hydrogen oxidation (Supplementary File S8). [NiFe]-hydrogenases 
716 associated with Comamonadaceae and Desulfovibrionales, which dominate the bacterial

717 communities of the ultrabasic springs, were abundant in the metagenomic data from these

718 springs. The Comamonadaceae $16 \mathrm{~S}$ rRNA, [NiFe]-hydrogenase, and Rubisco sequences are

719 highly similar to those reported for Comamonadaceae from other continental sites of

720 serpentinization including the Cabeço de Vide Aquifer (Tiago \& Veríssimo, 2013), the

721 Tablelands Ophiolite (Brazelton, Nelson \& Schrenk, 2012), The Cedars (Suzuki et al., 2014),

722 and the Coast Range Ophiolite Microbial Observatory (Crespo-Medina et al., 2014). The

723 presence of these organisms in alkaline springs appears to be a consistent indicator of

724 serpentinization (Schrenk, Brazelton \& Lang, 2013), and the genus Serpentinomonas has been

725 proposed for them (Suzuki et al., 2014). Serpentinomonas 16S rRNA sequences have also been

726 recovered from surface carbonate deposits formed by a spring at the Voltri Massif near to those

727 reported in this study (Quéméneur et al., 2015), which is consistent with the interpretation that

728 these organisms live at the surface or the shallow subsurface where serpentinizing fluids mix

729 with the oxygenated atmosphere (Schrenk, Brazelton \& Lang, 2013; Brazelton et al., 2013).

730

731 By contrast, the Desulfovibrionales represented by ESOM Bin 5 appear to be anaerobic,

732 hydrogen-utilizing, sulfate-reducing bacteria and may live in anoxic, deep subsurface habitats

733 underlying the springs. These bacteria, like the methanogens described above, were most

734 abundant in the BR2 spring, which also contains higher sulfide levels. Therefore, this spring

735 appears to provide more direct access to organisms that may have been recently active in anoxic,

736 methanogenic, and sulfate-reducing subsurface habitats.

737 
738 [FeFe]-hydrogenase sequences were also abundant, and many were associated with the

739 unclassified Bacteroidetes group enriched in the ultrabasic springs (Figure 2). These genes are

740 typically involved in fermentative hydrogen production and appear to have a broad taxonomic

741 distribution in our study, as illustrated by their wide distribution in the ESOM (Figure 4B).

742 Clostridiales, which were also enriched in the springs, are expected to encode some of the

743 [FeFe]-hydrogenase sequences (e.g. Mei et al., 2014), but no ESOM bins with taxonomic

744 markers consistently classified as Clostridiales could be identified.

745

746 These results are consistent with previous observations of abundant hydrogenases in

747 metagenomic data from marine and continental serpentinite springs (Brazelton, Nelson \&

748 Schrenk, 2012). Phylogenetic analyses of those sequences indicated that [NiFe]-hydrogenases

749 associated with Comamonadaceae and [FeFe]-hydrogenases associated with Firmicutes are

750 likely to be involved in hydrogen consumption and production, respectively. The co-occurrence

751 of Betaproteobacteria (often order Burkholderiales, including family Comamonadaceae) and

752 Firmicutes (in particular order Clostridiales) is a common feature of serpentinite springs and

753 perhaps the mixing of deep subsurface and surface fluids in general (reviewed by Schrenk,

754 Brazelton \& Lang, 2013; see also Purkamo et al., 2016). This report contributes to that emerging

755 trend by providing another example of Comamonadaceae organisms with [NiFe]-hydrogenases

756 and also reports [NiFe]-hydrogenases in Desulfovibrionales and [FeFe]-hydrogenases in

757 Bacteroidetes in serpentinite springs for the first time.

758

759 Methanotrophy 
760 Aerobic methane oxidation was detected in all three of the ultrabasic springs in this study (Table

761 5), and the Methylococcaceae family of aerobic methanotrophs was among the most enriched

762 taxa in the ultrabasic springs (Figure 2). The genomic bin corresponding to this family (ESOM

763 Bin 4) includes sequences encoding both the particulate and soluble forms of methane

764 monooxygenase ( $p m o A B C$ and $m m o X Y B Z D C$ ). (Ward et al., 2004). Being aerobic, these bacteria

765 are unlikely to be active in anoxic subsurface environments. However, a completely surface-

766 exposed habitat also seems unlikely because they were not detected in a travertine deposit

767 formed by one of these springs (Quéméneur et al., 2015). Therefore, they may inhabit a shallow

768 subsurface mixing zone where low levels of oxygen reach methane-rich subsurface water,

769 similar to the inferred habitat for the aerobic, hydrogen-oxidizing Comamonadaceae described

770 above.

771

772 Fermentation

773 Multiple fermentation pathways were enriched in the ultrabasic springs, and fermentation genes

774 were widely distributed among metagenomic fragments in the ESOM (Figure 4). Candidate

775 Division OD1 (now called Parcubacteria) was enriched in the ultrabasic springs here and has also

776 been found in serpentinite springs at The Cedars that are expected to represent deeper,

777 subsurface habitats (Suzuki et al., 2013). These bacteria are expected to be involved with

778 fermentation (Hu et al., 2016), but we were unable to verify this due to the lack of any ESOM

779 bins with a strong representation of Candidate Division OD1. Additional work will be required

780 to better characterize the genomes of these organisms, which have been reported to be small and

781 lacking genes typically thought to be essential for basic cellular processes (Nelson \& Stegen,

782 2015; Brown et al., 2015). 
784 An uncultured group of Bacteroidetes known as 'ML635J-40 aquatic group' was also enriched in

785 the ultrabasic springs and was well-represented in the ESOM. The bin of metagenomic

786 sequences associated with this group (ESOM Bin 3) encoded proteins predicted to be involved in

787 pyruvate fermentation, sugar uptake, and hydrogen production. A member of ML635J-40 aquatic

788 group was recently identified in a $\mathrm{pH} 10$ anaerobic reactor in which it was predicted to be

789 primarily responsible for hydrolysis of organic matter and supply of hydrogen gas to

790 methanogens (Nolla-Ardèvol, Strous \& Tegetmeyer, 2015). The Bacteroidetes in the BR2 and

791 GOR34 ultrabasic springs could have a similar syntrophic relationship with methanogens,

792 although the source of hydrolyzable organic matter in this case is unclear. The ML635J-40

793 aquatic group was not detected in a previous study of surface travertine deposits (Quéméneur et

794 al., 2015), indicating that they do not inhabit a completely surface-exposed environment.

795 Although great care was taken to avoid surface contamination during field sampling, including

796 measures to sample the subsurface source of the spring rather than the overlying pool (see

797 Methods), it remains possible that the Bacteroidetes sequences in the GOR34 springs represent

798 pool-dwelling organisms that are dependent on terrestrial organic matter that falls into the

799 surface-exposed pools. This interpretation is consistent with the lower abundance of

800 Bacteroidetes in the BR2 spring (Supplementary File S6), which is not submerged by an

801 overlying pool (Figure 1). It is also possible that they inhabit a shallow subsurface transition

802 zone, similar to that inferred above for the Comamonadaceae and Methylococcaceae. Future

803 studies should investigate the carbon source for these organisms in order to determine whether

804 they are supported by compounds synthesized by subsurface serpentinization-associated

805 reactions. 
807 Formate and acetate metabolism

808 Both formate and acetate are present at elevated concentrations in fluids venting from the

809 chimneys of the Lost City hydrothermal field (Lang et al., 2010), and formate is expected to be

810 an abiogenic product of serpentinization-associated reactions (Shock, 1992; Shock \& Schulte,

811 1998; McCollom \& Seewald, 2001, 2003; Seewald, Zolotov \& McCollom, 2006). Metagenomic

812 sequences predicted to encode proteins associated with formate and acetate metabolism were

813 abundant (Supplementary File S8) and widespread among taxa (green and blue points,

814 respectively, in Figure 4B) in the combined-spring assembly, including the ESOM bins

815 representing Methylococcaceae and Desulfovibrionales (Table 4). The wide taxonomic

816 distribution of these genes (formate c-acetyltransferase, formate dehydrogenase, acetate kinase,

817 phosphotransacetylase, AMP-forming acetyl-CoA synthetase, and carbon monoxide

818 dehydrogenase / acetyl-CoA decarbonylase/synthase (Cdh/ACDS)) clearly indicates that they are

819 not restricted to methanogens in this system and that this ecosystem features a broad metabolic

820 potential for utilizing formate and acetate. We measured organic acid concentrations in Voltri

821 Massif springs in 2010, before the microbiological studies described here. Formate and acetate

822 were present at low but detectable concentrations ( 0.4 and $2.7 \mu \mathrm{M}$, respectively) at GOR34-

823 spring3 and were below detection in all other springs. It is unclear whether the low levels

824 indicate a lack of production or rapid consumption, but our initial metabolic activity assays have

825 demonstrated that acetate can be oxidized to carbon dioxide at in situ conditions characterized by

826 extremely high $\mathrm{pH}$. Additional work is required to test whether the availability of formate and

827 acetate are correlated with the activity of specific genes, including those identified by this study.

828 Furthermore, future studies should attempt to demonstrate in the case of each group of organisms 
829 reported here whether formate and acetate are consumed or produced, whether they are cycled

830 intracellularly, and whether they are obtained from or released into the environment.

831

\section{Conclusions}

833 The potential significance of serpentinization-supported microbial ecosystems has been widely

834 recognized since the discovery of the Lost City hydrothermal field (Kelley et al., 2001), but we

835 are still in the early stages of characterizing the organisms and pathways that may benefit from

836 the subsurface geochemical reactions associated with serpentinization. This study of ultrabasic

837 springs at the Voltri Massif, Italy provides the first evidence for active methanogenesis and

838 aerobic methanotrophy in continental serpentinite springs as well as genomic information about

839 the specific organisms likely to be responsible for these processes. Both methanogenesis and

840 methanotrophy were active at very high $\mathrm{pH}$, potentially raising the upper $\mathrm{pH}$ limit known to

841 support both processes. These potential activity experiments were not intended to quantify in situ

842 rates, however, and do not preclude the possibility that the vast majority of methane in these

843 springs is produced by non-biological processes. The data reported here also contribute

844 additional metagenomic evidence for the importance of hydrogenases involved in both the

845 consumption and production of hydrogen gas in serpentinite systems.

846

847 The unavailability of inorganic carbon at the extremely high $\mathrm{pH}$ of these springs is likely to be a

848 limiting factor for autotrophic activity, and small organic compounds such as formate, acetate,

849 and methanol may serve as the primary carbon sources in such ecosystems. The absence of genes

850 in the Methanobacteriaceae bin required for the reduction of carbon dioxide may be a reflection

851 of the lack of inorganic carbon in this system. Furthermore, we found evidence for inorganic 
852 carbon as a substrate for methanogenesis only after it had been liberated by the oxidation of

853 acetate. The genetic potential for metabolism of formate and acetate is widespread among taxa in

854 this environment, which is consistent with an ecosystem being at least partially supported by

855 organic carbon synthesized by subsurface serpentinization-associated reactions.

856

857 These genomic and metabolic data were obtained despite the extremely low biomass of these

858 springs, suggesting that our results are the first clues into the few organisms capable of survival,

859 and potentially growth, in the harsh conditions of the $\mathrm{pH} 12$ springs. Because many of these

860 organisms were only found in the spring waters and not in surface travertine deposits

861 (Quéméneur et al., 2015), they are likely to represent inhabitants of subsurface environments in

862 the serpentinite rocks underlying the springs. Many of these putative subsurface organisms may

863 have been plucked from dense biofilm communities attached to serpentinites and then flushed

864 out to the surface by the spring water. Residence times of $\sim 700$ years have been estimated for

865 spring water in this system (Cipolli et al., 2004), suggesting that the subsurface communities

866 inferred by this study may persist for long time periods in isolation from the surface. We

867 anticipate that the metagenomic inventories and data analysis tools described here will provide a

868 foundation for future studies to investigate how these organisms make a living in such unusual

869 conditions and to test whether such ecosystems can be supported solely by subsurface

870 serpentinization-associated reactions.

871

872 Acknowledgements

873 We are grateful to have had access to the excellent facilities of the ETH Stable Isotope Lab

874 directed by Stefano Bernasconi. Esther Schwarzenbach, Melitza Crespo-Medina, Bridget Nelson, 
875 and Elena Amador provided valuable assistance and fun conversations in the field. Hilary

876 Morrison, Sharon Grim, Mitch Sogin, and Rick Colwell facilitated the early stages of this project

877 through the Census of Deep Life.

878

879

References

880

Abubucker S., Segata N., Goll J., Schubert AM., Izard J., Cantarel BL., Rodriguez-Mueller B.,

881 Zucker J., Thiagarajan M., Henrissat B., White O., Kelley ST., Methé B., Schloss PD.,

882

883

884 Gevers D., Mitreva M., Huttenhower C. 2012. Metabolic reconstruction for metagenomic

885

886

887 data and its application to the human microbiome. PLoS Computational Biology

888 8:e1002358. DOI: 10.1371/journal.pcbi.1002358.

Albert DB., Martens CS. 1997. Determination of low-molecular-weight organic acid

889

Alt JC., Schwarzenbach EM., Früh-Green GL., Shanks WC., Bernasconi SM., Garrido CJ., concentrations in seawater and pore-water samples via HPLC. Marine Chemistry 56:27-37.

890 Crispini L., Gaggero L., Padrón-Navarta JA., Marchesi C. 2013. The role of serpentinites in

891

892

893 cycling of carbon and sulfur: Seafloor serpentinization and subduction metamorphism. Lithos 178:40-54. DOI: 10.1016/j.lithos.2012.12.006.

Anders S., Pyl PT., Huber W. 2015. HTSeq--a Python framework to work with high-throughput

894 sequencing data. Bioinformatics 31:166-9. DOI: 10.1093/bioinformatics/btu638.

Blanco Y., Rivas LA., García-Moyano A., Aguirre J., Cruz-Gil P., Palacín A., van Heerden E., Parro V. 2014. Deciphering the Prokaryotic Community and Metabolisms in South African

898 Deep-Mine Biofilms through Antibody Microarrays and Graph Theory. PLoS ONE

901

Boisvert S., Raymond F., Godzaridis E., Laviolette F., Corbeil J. 2012. Ray Meta: scalable de 902 903 novo metagenome assembly and profiling. Genome Biology 13:R122. DOI: 10.1186/gb-

904 2012-13-12-r122.

905

Boulart C., Chavagnac V., Monnin C., Delacour A., Ceuleneer G., Hoareau G. 2013. Differences

906 in gas venting from ultramafic-hosted warm springs: The example of Oman and Voltri ophiolites. Ofioliti 38:143-156. DOI: 10.4454/ofioliti.v38i2.423. 
907 Bradley A., Hayes J., Summons R. 2009. Extraordinary ${ }^{13} \mathrm{C}$ enrichment of diether lipids at the 908 Lost City hydrothermal field indicates a carbon-limited ecosystem. Geochimica et 909 Cosmochimica Acta 73:102-118. DOI: 10.1016/j.gca.2008.10.005.

910 Brazelton WJ., Schrenk MO., Kelley DS., Baross JA. 2006. Methane- and sulfur-metabolizing 911 microbial communities dominate the Lost City hydrothermal field ecosystem. Applied and 912 Environmental Microbiology 72:6257-6270. DOI: 10.1128/AEM.00574-06.

913 Brazelton WJ., Mehta MP., Kelley DS., Baross JA. 2011. Physiological Differentiation within a 914 Single-Species Biofilm Fueled by Serpentinization. mBio 2:e00127-11. DOI:

$915 \quad$ 10.1128/mBio.00127-11.

916 Brazelton WJ., Morrill PL., Szponar N., Schrenk MO. 2013. Bacterial communities associated 917 with subsurface geochemical processes in continental serpentinite springs. Applied and 918 Environmental Microbiology 79:3906-16. DOI: 10.1128/AEM.00330-13.

919 Brazelton WJ., Nelson B., Schrenk MO. 2012. Metagenomic evidence for $\mathrm{H}_{2}$ oxidation and $\mathrm{H}_{2}$ 920 production by serpentinite-hosted subsurface microbial communities. Frontiers in Microbiology 2:268. DOI: 10.3389/fmicb.2011.00268.

Brown CT., Hug LA., Thomas BC., Sharon I., Castelle CJ., Singh A., Wilkins MJ., Wrighton KC., Williams KH., Banfield JF. 2015. Unusual biology across a group comprising more than 15\% of domain Bacteria. Nature 523:208-11. DOI: 10.1038/nature14486.

925

926

Bruni J., Canepa M., Chiodini G., Cioni R., Cipolli F., Longinelli A., Marini L., Ottonello G., Vetuschi M. 2002. Irreversible water-rock mass transfer accompanying the generation of

927

928

929

930

931

932

933

934

935

936

937

938

939 the neutral, $\mathrm{Mg}-\mathrm{HCO}_{3}$ and high- $\mathrm{pH}, \mathrm{Ca}-\mathrm{OH}$ spring waters of the Genova province, Italy. Applied Geochemistry 17:455-474. DOI: 10.1016/S0883-2927(01)00113-5.

Cardace D., Hoehler T., McCollom T., Schrenk M., Carnevale D., Kubo M., Twing K. 2013. Establishment of the Coast Range ophiolite microbial observatory (CROMO): drilling objectives and preliminary outcomes. Scientific Drilling 16:45-55. DOI: 10.5194/sd-16-452013.

Caspi R., Altman T., Billington R., Dreher K., Foerster H., Fulcher CA., Holland TA., Keseler IM., Kothari A., Kubo A., Krummenacker M., Latendresse M., Mueller LA., Ong Q., Paley S., Subhraveti P., Weaver DS., Weerasinghe D., Zhang P., Karp PD. 2014. The MetaCyc database of metabolic pathways and enzymes and the BioCyc collection of Pathway/Genome Databases. Nucleic Acids Research 42:D459-71. DOI: 10.1093/nar/gkt1103.

940

Cipolli F., Gambardella B., Marini L., Ottonello G. 2004. Geochemistry of high-pH waters from serpentinites of the Gruppo di Voltri (Genova, Italy) and reaction path modeling of $\mathrm{CO}_{2}$ 
941

942

943

944

945

946

947

948

949

950

951

952

953

954

955

956

957

958

959

960

961

962

963

964

965

966

967

968

969

970

971

972

sequestration in serpentinite aquifers. Applied Geochemistry 19:787-802. DOI:

10.1016/j.apgeochem.2003.10.007.

Cline JD. 1969. Spectrophotometric determination of hydrogen sulfide in natural waters.

Limnology and Oceanography 14:454-458. DOI: 10.4319/1o.1969.14.3.0454.

Colby J., Stirling DI., Dalton H. 1977. The soluble methane mono-oxygenase of Methylococcus capsulatus (Bath). Its ability to oxygenate n-alkanes, n-alkenes, ethers, and alicyclic, aromatic and heterocyclic compounds. The Biochemical Journal 165:395-402.

Consortium TU. 2015. UniProt: a hub for protein information. Nucleic Acids Research 43:D204D212. DOI: 10.1093/nar/gku989.

Crespo-Medina M., Twing KI., Kubo MDY., Hoehler TM., Cardace D., McCollom T., Schrenk MO. 2014. Insights into environmental controls on microbial communities in a continental serpentinite aquifer using a microcosm-based approach. Frontiers in Microbiology 5:604. DOI: $10.3389 /$ fmicb.2014.00604.

Darling AE., Jospin G., Lowe E., Matsen FA., Bik HM., Eisen JA. 2014. PhyloSift: phylogenetic analysis of genomes and metagenomes. PeerJ 2:e243. DOI: 10.7717/peerj.243.

Dick GJ., Andersson AF., Baker BJ., Simmons SL., Thomas BC., Yelton AP., Banfield JF. 2009. Community-wide analysis of microbial genome sequence signatures. Genome Biology 10:R85. DOI: 10.1186/gb-2009-10-8-r85.

Edgar RC., Haas, BJ., Clemente JC., Quince C., Knight R. 2011. UCHIME improves sensitivity and speed of chimera detection. Bioinformatics 27:2194.

Ferry JG. 2010. How to make a living by exhaling methane. Annual Review of Microbiology 64:453-73. DOI: 10.1146/annurev.micro.112408.134051.

Fricke WF., Seedorf H., Henne A., Kruer M., Liesegang H., Hedderich R., Gottschalk G., Thauer RK. 2006. The genome sequence of Methanosphaera stadtmanae reveals why this human intestinal archaeon is restricted to methanol and $\mathrm{H}_{2}$ for methane formation and ATP synthesis. Journal of Bacteriology 188:642-658. DOI: 10.1128/JB.188.2.642-658.2006.

Gomez-Alvarez V., Teal TK., Schmidt TM. 2009. Systematic artifacts in metagenomes from complex microbial communities. The ISME Journal 3:1314-7. DOI: 10.1038/ismej.2009.72.

Hu P., Tom L., Singh A., Thomas BC., Baker BJ., Piceno YM., Andersen GL., Banfield JF. 2016. Genome-Resolved Metagenomic Analysis Reveals Roles for Candidate Phyla and Other Microbial Community Members in Biogeochemical Transformations in Oil Reservoirs. mBio 7:e01669-15. DOI: 10.1128/mBio.01669-15. 
973 Huber JA., Butterfield DA., Baross JA. 2002. Temporal changes in archaeal diversity and

974

975

976

977

978

979

980

981

982

983

984

985

986

987

988

989

990

991

992

993

994

995

996

997

998

999

1000

1001

1002

1003

1004

1005

1006

1007

chemistry in a mid-ocean ridge subseafloor habitat. Applied and Environmental

Microbiology 68:1585-1594. DOI: 10.1128/AEM.68.4.1585-1594.2002.

Huse SM., Young VB., Morrison HG., Antonopoulos DA., Kwon J., Dalal S., Arrieta R., Hubert NA., Shen L., Vineis JH., Koval JC., Sogin ML., Chang EB., Raffals LE. 2014a.

Comparison of brush and biopsy sampling methods of the ileal pouch for assessment of mucosa-associated microbiota of human subjects. Microbiome 2:5. DOI: 10.1186/20492618-2-5.

Huse SM., Mark Welch DB., Voorhis A., Shipunova A., Morrison HG., Eren A., Sogin ML. 2014b. VAMPS: a website for visualization and analysis of microbial population structures. BMC Bioinformatics 15:41. DOI: 10.1186/1471-2105-15-41.

Hyatt D., Chen G-L., LoCascio PF., Land ML., Larimer FW., Hauser LJ. 2010. Prodigal: prokaryotic gene recognition and translation initiation site identification. $B M C$ Bioinformatics 11:119. DOI: 10.1186/1471-2105-11-119.

Kelley DS., Karson JA., Blackman DK., Fruh-Green GL., Butterfield DA., Lilley MD., Olson EJ., Schrenk MO., Roe KK., Lebon GT., Rivizzigno P. 2001. An off-axis hydrothermal vent field near the Mid-Atlantic Ridge at $30^{\circ}$ N. Nature 412:145-149. DOI: $10.1038 / 35084000$.

Kelley DS., Karson JA., Früh-Green GL., Yoerger DR., Shank TM., Butterfield DA., Hayes JM., Schrenk MO., Olson EJ., Proskurowski G., Jakuba M., Bradley A., Larson B., Ludwig K., Glickson D., Buckman K., Bradley AS., Brazelton WJ., Roe K., Elend MJ., Delacour A., Bernasconi SM., Lilley MD., Baross JA., Summons RE., Sylva SP. 2005. A serpentinitehosted ecosystem: the Lost City hydrothermal field. Science 307:1428-34. DOI: 10.1126/science. 1102556 .

Kohl L., Cumming E., Cox A., Rietze A., Morrissey L., Lang SQ., Richter A., Suzuki S., Nealson KH., Morrill PL. 2016. Exploring the metabolic potential of microbial communities in ultra-basic, reducing springs at The Cedars, CA, USA: Experimental evidence of microbial methanogenesis and heterotrophic acetogenesis. Journal of Geophysical Research: Biogeosciences 121:1203-1220. DOI: 10.1002/2015JG003233.

Lang SQ., Butterfield DA., Schulte M., Kelley DS., Lilley MD. 2010. Elevated concentrations of formate, acetate and dissolved organic carbon found at the Lost City hydrothermal field. Geochimica et Cosmochimica Acta 74:941-952. DOI: 10.1016/j.gca.2009.10.045.

Lang SQ., Früh-Green GL., Bernasconi SM., Lilley MD., Proskurowski G., Méhay S., Butterfield DA. 2012. Microbial utilization of abiogenic carbon and hydrogen in a serpentinite-hosted system. Geochimica et Cosmochimica Acta 92:82-99. DOI: 10.1016/j.gca.2012.06.006. 
1008 Langmead B., Salzberg SL. 2012. Fast gapped-read alignment with Bowtie 2. Nature Methods 1009 9:357-9. DOI: 10.1038/nmeth.1923.

1010 Martin M. 2011. Cutadapt removes adapter sequences from high-throughput sequencing reads. EMBnet.journal 17:10. DOI: 10.14806/ej.17.1.200.

1012 McCollom T., Seewald J. 2001. A reassessment of the potential for reduction of dissolved $\mathrm{CO}_{2}$

1013

1014

1015

1016

1017

1018

1019

1020

1021

1022

1023

1024

1025

1026

1027

1028

1029

1030

1031

1032

1033

1034

1035

1036

1037

1038

1039

1040 to hydrocarbons during serpentinization of olivine. Geochimica et Cosmochimica Acta 65:3769-3778. DOI: 10.1016/S0016-7037(01)00655-X.

McCollom TM., Seewald JS. 2003. Experimental study of the hydrothermal reactivity of organic acids and acid anions: II. Acetic acid, acetate, and valeric acid. Geochimica et Cosmochimica Acta 67:3645-3664. DOI: 10.1016/S0016-7037(03)00135-2.

McMurdie PJ., Holmes S. 2013. phyloseq: an R package for reproducible interactive analysis and graphics of microbiome census data. PloS ONE 8:e61217. DOI: 10.1371/journal.pone.0061217.

McMurdie PJ., Holmes S. 2014. Waste not, want not: why rarefying microbiome data is inadmissible. PLoS Computational Biology 10:e1003531. DOI: 10.1371/journal.pcbi.1003531.

Méhay S., Früh-Green G., Lang S., Bernasconi S., Brazelton W., Schrenk M., Schaeffer P., Adam P. 2013. Record of archaeal activity at the serpentinite-hosted Lost City Hydrothermal Field. Geobiology 11:570-592. DOI: 10.1111/gbi.12062.

Mei N., Zergane N., Postec A., Erauso G., Ollier A., Payri C., Pelletier B., Fardeau ML., Ollivier B., Quéméneur M. 2014. Fermentative hydrogen production by a new alkaliphilic Clostridium sp. (strain PROH2) isolated from a shallow submarine hydrothermal chimney in Prony Bay, New Caledonia. International Journal of Hydrogen Energy 39:19465-19473. DOI: 10.1016/j.jhydene.2014.09.111.

Morrill PL., Kuenen JG., Johnson OJ., Suzuki S., Rietze A., Sessions AL., Fogel ML., Nealson KH. 2013. Geochemistry and geobiology of a present-day serpentinization site in California: The Cedars. Geochimica et Cosmochimica Acta 109:222-240. DOI: 10.1016/j.gca.2013.01.043.

Morrill PL., Brazelton WJ., Kohl L., Rietze A., Miles SM., Kavanagh H., Schrenk MO., Ziegler SE., Lang SQ. 2014. Investigations of potential microbial methanogenic and carbon monoxide utilization pathways in ultra-basic reducing springs associated with present-day continental serpentinization: the Tablelands, NL, CAN. Frontiers in Microbiology 5:613. DOI: $10.3389 /$ fmicb.2014.00613. 
1041 Nelson MC., Morrison HG., Benjamino J., Grim SL., Graf J. 2014. Analysis, Optimization and 1042 Verification of Illumina-Generated 16S rRNA Gene Amplicon Surveys. PLoS ONE 1043 9:e94249. DOI: 10.1371/journal.pone.0094249.

1044 Nelson WC., Stegen JC. 2015. The reduced genomes of Parcubacteria (OD1) contain signatures 1045 of a symbiotic lifestyle. Frontiers in Microbiology 6:713. DOI: 10.3389/fmicb.2015.00713.

1046 Nolla-Ardèvol V., Strous M., Tegetmeyer HE. 2015. Anaerobic digestion of the microalga Spirulina at extreme alkaline conditions: biogas production, metagenome, and metatranscriptome. Frontiers in Microbiology 6:597. DOI: 10.3389/fmicb.2015.00597. Encyclopedia of Genes and Genomes. Nucleic Acids Research 27:29-34. DOI: 10.1093/nar/27.1.29.

Parks DH., Imelfort M., Skennerton CT., Hugenholtz P., Tyson GW. 2015. CheckM: assessing the quality of microbial genomes recovered from isolates, single cells, and metagenomes. Genome Research 25:1043-1055. DOI: 10.1101/gr.186072.114.

Pikuta E V., Hoover RB., Bej AK., Marsic D., Whitman WB., Cleland D., Krader P. 2003. Desulfonatronum thiodismutans sp. nov., a novel alkaliphilic, sulfate-reducing bacterium capable of lithoautotrophic growth. International Journal of Systematic and Evolutionary Microbiology 53:1327-32. DOI: 10.1099/ijs.0.02598-0.

Prestat E., David MM., Hultman J., Taş N., Lamendella R., Dvornik J., Mackelprang R., Myrold DD., Jumpponen A., Tringe SG., Holman E., Mavromatis K., Jansson JK. 2014. FOAM (Functional Ontology Assignments for Metagenomes): a Hidden Markov Model (HMM) database with environmental focus. Nucleic Acids Research 42:e145. DOI:

1064 10.1093/nar/gku702.

Proskurowski G., Lilley MD., Seewald JS., Früh-Green GL., Olson EJ., Lupton JE., Sylva SP., Kelley DS. 2008. Abiogenic hydrocarbon production at Lost City Hydrothermal Field.

1067 Pruesse E., Peplies J., Glöckner FO. 2012. SINA: accurate high-throughput multiple sequence alignment of ribosomal RNA genes. Bioinformatics 28:1823-9. DOI:

1070 Purkamo L., Bomberg M., Kietäväinen R., Salavirta H., Nyyssönen M., Nuppunen-Puputti M., Ahonen L., Kukkonen I., Itävaara M. 2016. Microbial co-occurrence patterns in deep

1074 Quéméneur M., Bes M., Postec A., Mei N., Hamelin J., Monnin C., Chavagnac V., Payri C., 1075 Pelletier B., Guentas-Dombrowsky L., Gérard M., Pisapia C., Gérard E., Ménez B., Ollivier 
1076

1077

1078

1079

1080

1081

1082

1083

1084

1085

1086

1087

1088

1089

1090

1091

1092

1093

1094

1095

1096

1097

1098

1099

1100

1101

1102

1103

1104

1105

1106

1107

1108

1109

B., Erauso G. 2014. Spatial distribution of microbial communities in the shallow submarine alkaline hydrothermal field of the Prony Bay, New Caledonia. Environmental Microbiology Reports 33. DOI: 10.1111/1758-2229.12184.

Quéméneur M., Palvadeau A., Postec A., Monnin C., Chavagnac V., Ollivier B., Erauso G. 2015. Endolithic microbial communities in carbonate precipitates from serpentinite-hosted hyperalkaline springs of the Voltri Massif (Ligurian Alps, Northern Italy). Environmental Science and Pollution Research 22:13613-24. DOI: 10.1007/s11356-015-4113-7.

Rahalkar M., Bussmann I., Schink B. 2007. Methylosoma difficile gen. nov., sp. nov., a novel methanotroph enriched by gradient cultivation from littoral sediment of Lake Constance. International Journal of Systematic and Evolutionary Microbiology 57:1073-1080. DOI: 10.1099/ijs.0.64574-0.

Robinson MD., McCarthy DJ., Smyth GK. 2010. edgeR: a Bioconductor package for differential expression analysis of digital gene expression data. Bioinformatics 26:139-40. DOI: 10.1093/bioinformatics/btp616.

Sánchez-Murillo R., Gazel E., Schwarzenbach EM., Crespo-Medina M., Schrenk MO., Boll J., Gill BC. 2014. Geochemical evidence for active tropical serpentinization in the Santa Elena Ophiolite, Costa Rica: An analog of a humid early Earth? Geochemistry Geophysics Geosystems 15:1783-1800. DOI: 10.1002/2013GC005213.

Schloss PD., Westcott SL., Ryabin T., Hall JR., Hartmann M., Hollister EB., Lesniewski RA., Oakley BB., Parks DH., Robinson CJ., Sahl JW., Stres B., Thallinger GG., Van Horn DJ., Weber CF. 2009. Introducing mothur: Open Source, Platform-independent, CommunitySupported Software for Describing and Comparing Microbial Communities. Applied and Environmental Microbiology 75:7537-7541. DOI: 10.1128/AEM.01541-09.

Schloss PD., Gevers D., Westcott SL. 2011. Reducing the Effects of PCR Amplification and Sequencing Artifacts on 16S rRNA-Based Studies. PLoS ONE 6:e27310. DOI: 10.1371/journal.pone.0027310.

Schrenk MO., Kelley DS., Bolton SA., Baross JA. 2004. Low archaeal diversity linked to subseafloor geochemical processes at the Lost City Hydrothermal Field, Mid-Atlantic Ridge. Environmental Microbiology 6:1086-1095. DOI: 10.1111/j.1462-2920.2004.00650.x.

Schrenk MO., Brazelton WJ., Lang SQ. 2013. Serpentinization, Carbon, and Deep Life. Reviews in Mineralogy and Geochemistry 75:575-606. DOI: 10.2138/rmg.2013.75.18.

Schwarzenbach EM., Lang SQ., Früh-Green GL., Lilley MD., Bernasconi SM., Méhay S. 2013. Sources and cycling of carbon in continental, serpentinite-hosted alkaline springs in the Voltri Massif, Italy. Lithos 177:226-244. DOI: 10.1016/j.lithos.2013.07.009. 
1110 Seemann T. 2014. Prokka: rapid prokaryotic genome annotation. Bioinformatics 30:2068-9. DOI:

$1111 \quad$ 10.1093/bioinformatics/btu153.

1112 Seewald JS., Zolotov MY., McCollom T. 2006. Experimental investigation of single carbon

1113 compounds under hydrothermal conditions. Geochimica et Cosmochimica Acta 70:446-460.

1114 DOI: $10.1016 /$ j.gca.2005.09.002.

1115 Shock E. 1992. Stability of peptides in high-temperature aqueous solutions. Geochimica et

1116 Cosmochimica Acta 56:3481-3491. DOI: 10.1016/0016-7037(92)90392-V.

1117 Shock EL., Schulte MD. 1998. Organic synthesis during fluid mixing in hydrothermal systems.

1118 Journal of Geophysical Research 103:28,513-28,527. DOI: 199810.1029/98JE02142.

1119 Sogin ML., Morrison HG., Huber JA., Mark Welch D., Huse SM., Neal PR., Arrieta JM., Herndl

1120 GJ. 2006. Microbial diversity in the deep sea and the underexplored "rare biosphere".

1121 Proceedings of the National Academy of Sciences of the United States of America

1122 103:12115-12120. DOI: 10.1073/pnas.0605127103.

1123 Suzuki S., Ishii S., Wu A., Cheung A., Tenney A., Wanger G., Kuenen JG., Nealson KH. 2013.

1124 Microbial diversity in The Cedars, an ultrabasic, ultrareducing, and low salinity

1125 serpentinizing ecosystem. Proceedings of the National Academy of Sciences of the United

1126 States of America 110:15336-41. DOI: 10.1073/pnas.1302426110.

1127 Suzuki S., Kuenen JG., Schipper K., van der Velde S., Ishii S., Wu A., Sorokin DY., Tenney A.,

1128 Meng X., Morrill PL., Kamagata Y., Muyzer G., Nealson KH. 2014. Physiological and

1129

1130

1131 genomic features of highly alkaliphilic hydrogen-utilizing Betaproteobacteria from a

1132 continental serpentinizing site. Nature Communications 5:3900. DOI:

1133 10.1038/ncomms4900.

1134

Tiago I., Veríssimo A. 2013. Microbial and functional diversity of a subterrestrial high $\mathrm{pH}$ groundwater associated to serpentinization. Environmental Microbiology 15:1687-1706.

1135 DOI: $10.1111 / 1462-2920.12034$.

1136

1137

1138

Topçuoğlu BD., Stewart LC., Morrison HG., Butterfield DA., Huber JA., Holden JF. 2016. Hydrogen limitation and syntrophic growth among natural assemblages of thermophilic methanogens at deep-sea hydrothermal vents. Frontiers in Microbiology 7:1240. DOI: 10.3389/fmicb.2016.01240.

Ultsch A., Mörchen F. 2005. ESOM-Maps: tools for clustering, visualization, and classification with Emergent SOM. Technical Report Dept. of Mathematics and Computer Science,

1142 Wang DT., Gruen DS., Lollar BS., Hinrichs K., Stewart LC., Holden JF., Hristov AN., Pohlman 1143 JW., Morrill PL., Könneke M., Delwiche KB., Reeves EP., Sutcliffe N., Ritter DJ., Seewald 1144 JS., Jennifer C., Hemond HF., Kubo MD., Hoehler TM., Ono S. 2015. Nonequilibrium 
1145

1146

1147

1148

1149

1150

1151

1152

1153

1154

1155

1156

1157

1158

1159

1160

1161

1162

1163

1164

1165

1166

1167

1168

1169

1170

1171

1172

1173

1174

clumped isotope signals in microbial methane. Science 348:428-431. DOI: 10.1126/science.aaa4326.

Ward N., Larsen Ø., Sakwa J., Bruseth L., Khouri H., Durkin AS., Dimitrov G., Jiang L., Scanlan D., Kang KH., Lewis M., Nelson KE., Methé B., Wu M., Heidelberg JF., Paulsen IT., Fouts D., Ravel J., Tettelin H., Ren Q., Read T., DeBoy RT., Seshadri R., Salzberg SL., Jensen HB., Birkeland NK., Nelson WC., Dodson RJ., Grindhaug SH., Holt I., Eidhammer I., Jonasen I., Vanaken S., Utterback T., Feldblyum T V., Fraser CM., Lillehaug JR., Eisen JA. 2004. Genomic Insights into Methanotrophy: The Complete Genome Sequence of Methylococcus capsulatus (Bath). PLoS Biology 2:e303. DOI: 10.1371/journal.pbio.0020303.

Woycheese KM., Meyer-Dombard DR., Cardace D., Argayosa AM., Arcilla CA. 2015. Out of the dark: transitional subsurface-to-surface microbial diversity in a terrestrial serpentinizing seep (Manleluag, Pangasinan, the Philippines). Frontiers in Microbiology 6:44. DOI: 10.3389/fmicb.2015.00044.

Ye Y., Doak TG. 2009. A Parsimony Approach to Biological Pathway Reconstruction/Inference for Genomes and Metagenomes. PLoS Computational Biology 5:e1000465. DOI: 10.1371/journal.pcbi.1000465.

\section{Figure Captions}

Figure 1. Ultrabasic springs of the Voltri Massif in Italy were sampled at two locations: A)

GOR34, including two springs and an adjacent river and B) BR2, including one spring and an adjacent river. All water samples were collected by peristaltic pumping through a $0.2 \mu \mathrm{m}$ filter cartridge. Photo credits: W.J. Brazelton (A) and B. Nelson (B).

Figure 2. Taxonomic classifications of bacterial (A) and archaeal (B) operational taxonomic units (OTUs, defined as unique 16S rRNA sequences) that were identified as significantly enriched in the ultrabasic serpentinite spring GOR34-spring1 compared to the adjacent river. Each data point in the plots represents one OTU's mean abundance across all samples in the analysis and its differential abundance in the comparison GOR34-spring1 versus GOR34-river. 
1175 Mean abundance is reported as $\log _{2}$ counts per million; a value of 16 corresponds to 23,000

1176 sequences for that OTU. Red data points represent OTUs with differential abundances that are

1177 significantly enriched (false discovery rate < 0.05) in either GOR34-spring1 or GOR34-river.

1178 The relative abundances of these significantly enriched OTUs are reported as a percentage of all

1179 significantly enriched sequences and grouped into taxonomic classifications at the family level in

1180 the colored bar charts. Sections of the bar chart were labeled with the corresponding family

1181 where possible, and the abbreviations are defined by bold font in the right-hand legends.

1182

1183 Figure 3. Diagram of methanogenesis pathways from carbon dioxide, formate, acetate, methanol,

1184 and methylamines with associated protein homologs identified with KEGG IDs. Green-

1185 highlighted proteins are predicted to occur in the combined-spring metagenomic assembly, and

1186 yellow-highlighted proteins are predicted to occur in both the combined-spring and combined-

1187 river assemblies. The black border indicates proteins identified in the Methanobacteriaceae bin

1188 (ESOM Bin 1 in Figure 4 and Table 4). The diagram is modified from (Ferry, 2010).

1189

1190 Figure 4. An emergent self-organizing map (ESOM) constructed with the combined-spring

1191 metagenomic assembly. Each point represents a fragment of metagenomic assembly, and points

1192 are arranged in space according to the similarities of their tetranucleotide compositions. Dark

1193 gray areas are valleys where highly similar sequences cluster together. Light areas of the map are

1194 high topographic ridges that separate dissimilar sequences. The same ESOM is shown here twice:

1195 metagenomic fragments are color-coded in A) to indicate PhyloSift classifications of taxonomic

1196 markers and in B) to show which fragments are predicted to encode protein functions of 
1197 particular interest to this study. Based on this information, five bins of sequences were selected 1198 from the map for further evaluation (Table 4). 


\section{Table $\mathbf{1}$ (on next page)}

Chemical characteristics of ultrabasic springs and adjacent rivers of the Voltri Massif, Italy

Chemical characteristics of ultrabasic springs and adjacent rivers of the Voltri Massif, Italy 
Table 1. Chemical characteristics of ultrabasic springs and adjacent rivers of the Voltri Massif, Italy.

$\begin{array}{cccccccc}\text { Sample Name } & \mathbf{p H} & \begin{array}{c}\mathbf{E}_{\mathbf{h}} \\ (\mathbf{m V})\end{array} & \begin{array}{c}\mathbf{C H}_{\mathbf{4}} \\ \mathbf{( \mu M )}\end{array} & \begin{array}{c}\mathbf{H}_{\mathbf{2}} \\ \mathbf{( \mu \mathbf { M } )}\end{array} & \begin{array}{c}\mathbf{D I C} \\ \mathbf{( \mu \mathbf { M } )}\end{array} & \begin{array}{c}\text { Sulfate } \\ (\mathbf{\mu M})\end{array} & \begin{array}{c}\text { Sulfide } \\ (\mathbf{\mu M})\end{array} \\ \text { BR2-spring-2012 } & 12.1 & -195 & 689 & 0.5 & 29 & 6.5 & 16.5 \\ \text { BR2-spring-2013 } & 12.3 & -75 & 733 & 1.8 & 7.8 & \mathrm{~nm} & 16.2 \\ \text { BR2-river-2012 } & 8.1 & 450 & \text { bdl } & 0.2 & 3031 & 130 & \text { bdl } \\ \text { BR2-river-2013 } & 8.0 & 311 & \text { bdl } & \text { bdl } & 2678 & \mathrm{~nm} & \text { bdl } \\ \text { GOR34-spring1-2011 } & 12.2 & -60 & 155 & 3.9 & 14 & 3.0 & \text { bdl } \\ \text { GOR34-spring1-2013 } & 12.3 & -156 & 213 & 9.2 & 17.2 & \mathrm{~nm} & 18.6 \\ \text { GOR34-spring3-2012 } & 11.8 & -202 & 201 & 26.8 & 29 & \text { bdl } & 17.7 \\ \text { GOR34-river-2012 } & 9.3 & 360 & 0.1 & \text { bdl } & 1752 & 49 & 6.3 \\ \text { GOR34-river-2013 } & 9.5 & 240 & \text { bdl } & \text { bdl } & 1670 & \mathrm{~nm} & \text { bdl }\end{array}$

$\mathrm{nm}=$ not measured; $b d l=$ below detection limit 


\section{Table 2 (on next page)}

Water samples collected from ultrabasic springs for metagenomic analyses.

Water samples collected from ultrabasic springs for metagenomic analyses. 
Table 2. Water samples collected from ultrabasic springs for metagenomic analyses.

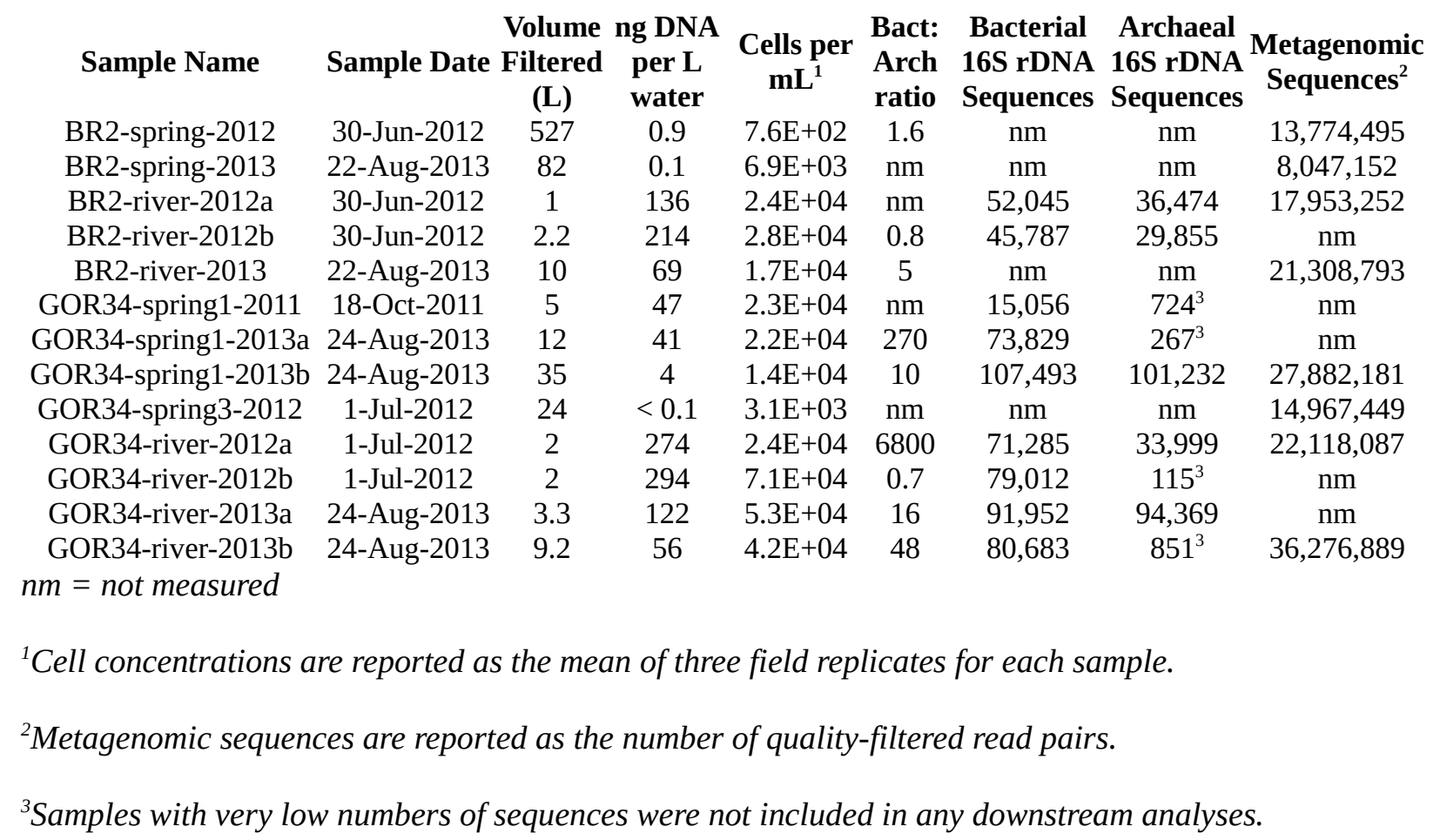




\section{Table 3(on next page)}

Assembly and annotation statistics for the pooled metagenomic assemblies and the five ESOM bins.

Assembly and annotation statistics for the pooled metagenomic assemblies and the five ESOM bins. 
Table 3. Assembly and annotation statistics for the pooled metagenomic assemblies and the five ESOM bins.

\# contigs ( $>=500$ bp)

\# contigs ( $>=25000 \mathrm{bp})$

Total length $(>=500 \mathrm{bp})$

Total length ( $>=25000 \mathrm{bp})$

Largest contig (bp)

N50 (length of median contig)

Predicted genes

Predicted protein-encoding genes

Predicted rRNA-encoding genes

Predicted tRNA-encoding genes

Predicted other RNA-encoding genes

Predicted proteins annotated with KEGG ${ }^{1}$

Predicted proteins annotated with UniprotKB

Predicted proteins annotated with Pfam

Predicted proteins annotated with HAMAP

Predicted proteins annotated with CLUSTERS

Predicted proteins with no annotation

$\begin{array}{cc}\text { combined- } & \text { combined- } \\ \text { spring } & \text { river } \\ 55,894 & 40,355 \\ 122 & 186 \\ 89,619,646 & 73,320,758 \\ 4,783,632 & 9,953,584 \\ 99,214 & 304,939 \\ 2,367 & 3,515 \\ 108,150 & 91,693 \\ 104,651 & 89,606 \\ 77 & 67 \\ 2,267 & 1,349 \\ 1,155 & 671 \\ 71,856 & 67,170 \\ 34 & 19 \\ 482 & 367 \\ 58 & 30 \\ 212 & 151 \\ 32,009 & 21,869\end{array}$

$\begin{array}{ccccc}\text { ESOM } & \text { ESOM } & \text { ESOM } & \text { ESOM } & \text { ESOM } \\ \text { Bin 1 } & \text { Bin 2 } & \text { Bin 3 } & \text { Bin 4 } & \text { Bin 5 } \\ 228 & 157 & 123 & 169 & 88 \\ 7 & 0 & 11 & 9 & 6 \\ 1,261,593 & 1,129,542 & 1,117,180 & 1,686,028 & 1,124,653 \\ 330,655 & 0 & 342,191 & 277,131 & 191,679 \\ 93,351 & 24,214 & 37,024 & 41,177 & 34,915 \\ 4,908 & 9,513 & 12,857 & 15,069 & 16,218 \\ 1,280 & 974 & 820 & 1,453 & 965 \\ 1,256 & 963 & 805 & 1,423 & 933 \\ 0 & 0 & 0 & 0 & 0 \\ 16 & 11 & 12 & 20 & 27 \\ 8 & 0 & 3 & 10 & 5 \\ 1,014 & 874 & 714 & 1,271 & 855 \\ 0 & 0 & 0 & 0 & 0 \\ 4 & 7 & 2 & 3 & 3 \\ 0 & 0 & 0 & 0 & 0 \\ 1 & 0 & 0 & 1 & 0 \\ 237 & 82 & 89 & 148 & 75\end{array}$

${ }^{1}$ Predicted proteins were first mapped to the KEGG database, and any remaining proteins without a predicted function were then mapped to the other databases. 


\section{Table 4 (on next page)}

Predicted metabolic pathways significantly enriched in ultrabasic spring metagenomes compared to adjacent rivers.

Predicted metabolic pathways significantly enriched in ultrabasic spring metagenomes compared to adjacent rivers. 
Table 4. Characteristics of ESOM bins identified in Figure 4.

\section{Completeness Contamination \\ Strain heterogeneity}

$1.2 \%$

Bin $1 \quad 44.11 \%$

Bin $2 \quad 42.16 \%$

Bin $3 \quad 27.59 \%$

Bin $4 \quad 47.98 \%$

Bin 5

$60.34 \%$
$11.72 \%$

$1.72 \%$

$6.24 \%$

$6.03 \%$
$75 \%$

$3.23 \%$

$0 \%$

$34.88 \%$

$100 \%$

\section{Taxonomy}

Methanobacteriacea

Comamonadaceae /

Xanthomonadaceae

Bacteroidetes

Methylococcaceae

Desulfovibrionales

\section{Metabolic Potential}

Methanogenesis; nitrogen fixation

Carbon fixation (Rubisco); organic carbon degradation

Hydrogen production; fermentation Methylotrophy

Hydrogen oxidation; dissimilatory sulfate reduction 
Table 5 (on next page)

Characteristics of ESOM bins identified in Figure 4.

Characteristics of ESOM bins identified in Figure 4. 
Table 5. Detection of metabolic activities in incubation experiments with spring water.

\begin{tabular}{|c|c|c|c|c|c|c|}
\hline & $\begin{array}{c}\text { BR2- } \\
\text { spring- } \\
2011\end{array}$ & $\begin{array}{c}\text { BR2- } \\
\text { spring- } \\
2012\end{array}$ & $\begin{array}{c}\text { GOR34- } \\
\text { spring1- } \\
2010\end{array}$ & $\begin{array}{c}\text { GOR34- } \\
\text { spring1- } \\
2012\end{array}$ & $\begin{array}{c}\text { GOR34- } \\
\text { spring3- } \\
2011\end{array}$ & $\begin{array}{c}\text { GOR34- } \\
\text { spring3- } \\
2012\end{array}$ \\
\hline $\mathrm{CO}_{2--}>\mathrm{CH}_{4}$ & - & - & - & - & $\mathrm{nm}$ & - \\
\hline formate $-->\mathrm{CH}_{4}$ & - & - & - & - & $\mathrm{nm}$ & - \\
\hline acetate- $\mathrm{C}_{1}-->\mathrm{CH}_{4}$ & - & - & - & - & +++ & - \\
\hline acetate- $\mathrm{C}_{2}-->\mathrm{CH}_{4}$ & - & - & - & - & - & - \\
\hline acetate- $\mathrm{C}_{1}-->\mathrm{CO}_{2}$ & - & $\mathrm{nm}$ & ++ & $\mathrm{nm}$ & ++ & $\mathrm{nm}$ \\
\hline acetate- $\mathrm{C}_{2}-->\mathrm{CO}_{2}$ & - & $\mathrm{nm}$ & + & $\mathrm{nm}$ & - & $\mathrm{nm}$ \\
\hline propionate --> $\mathrm{CO}_{2}$ & + & $\mathrm{nm}$ & - & $\mathrm{nm}$ & + & $\mathrm{nm}$ \\
\hline $\mathrm{CH}_{4}-->\mathrm{CO}_{2}$ & ++ & - & +++ & $++(+)^{*}$ & ++ & - \\
\hline
\end{tabular}

* Third (+) symbol indicates stronger signal when exposed to oxygen. 


\section{Figure 1}

Ultrabasic springs of the Voltri Massif in Italy were sampled at two locations.

A) GOR34, including two springs and an adjacent river and B) BR2, including one spring and an adjacent river. All water samples were collected by peristaltic pumping through a $0.2 \mu \mathrm{m}$ filter cartridge. Photo credits: W.J. Brazelton (A) and B. Nelson (B).

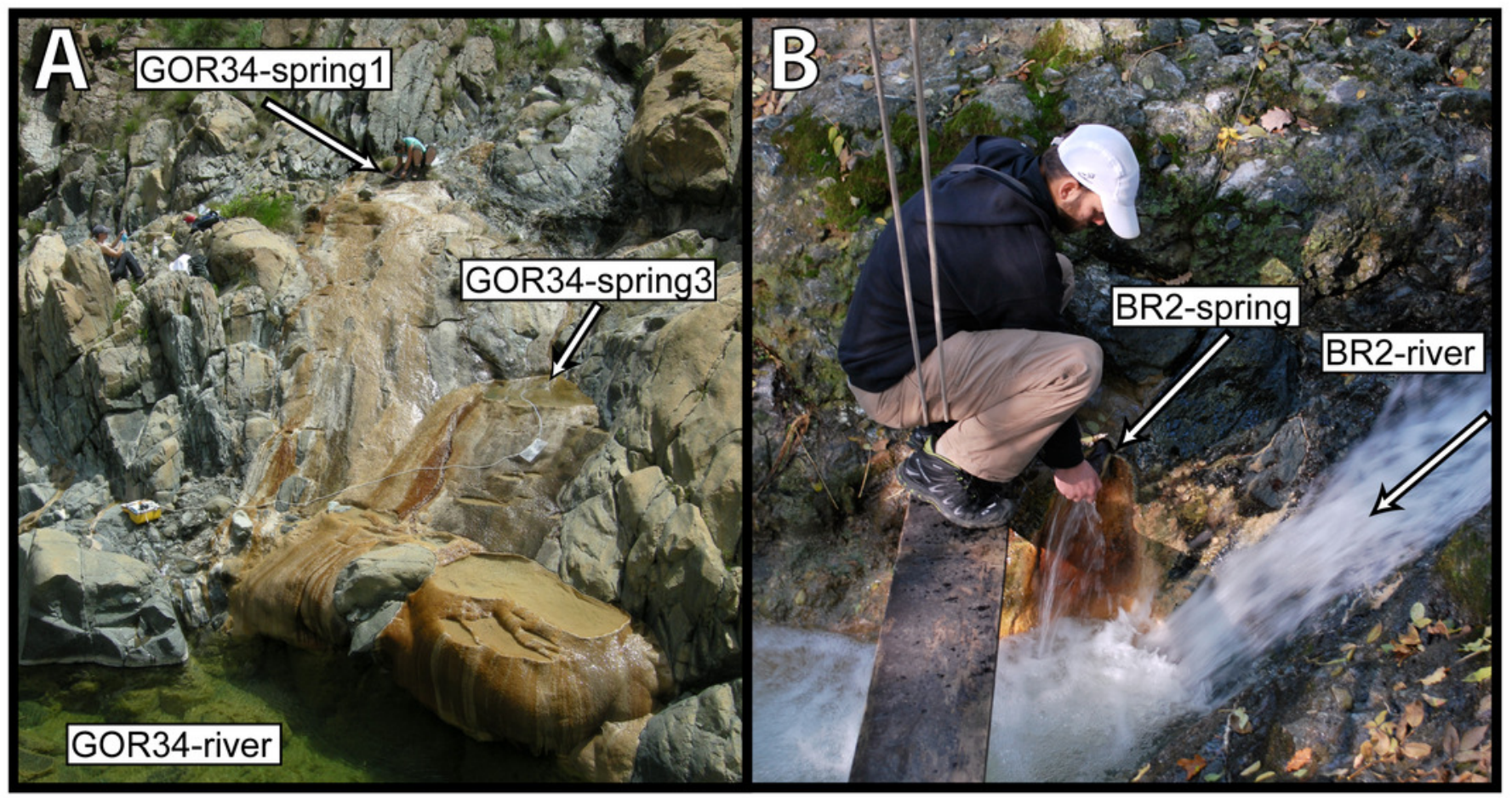




\section{Figure 2}

Bacterial and archaeal sequences enriched in ultrabasic springs.

Taxonomic classifications of bacterial (A) and archaeal (B) operational taxonomic units (OTUs, defined as unique $16 \mathrm{~S}$ rRNA sequences) that were identified as significantly enriched in the ultrabasic serpentinite spring GOR34-springl compared to the adjacent river. Each data point in the plots represents one OTU's mean abundance across all samples in the analysis and its differential abundance in the comparison GOR34-spring1 versus GOR34-river. Mean abundance is reported as $\log _{2}$ counts per million; a value of 16 corresponds to 23,000 sequences for that OTU. Red data points represent OTUs with differential abundances that are significantly enriched (false discovery rate $<0.05$ ) in either GOR34-spring1 or GOR34river. The relative abundances of these significantly enriched OTUs are reported as a percentage of all significantly enriched sequences and grouped into taxonomic classifications at the family level in the colored bar charts. Sections of the bar chart were labeled with the corresponding family where possible, and the abbreviations are defined by bold font in the right-hand legends. 

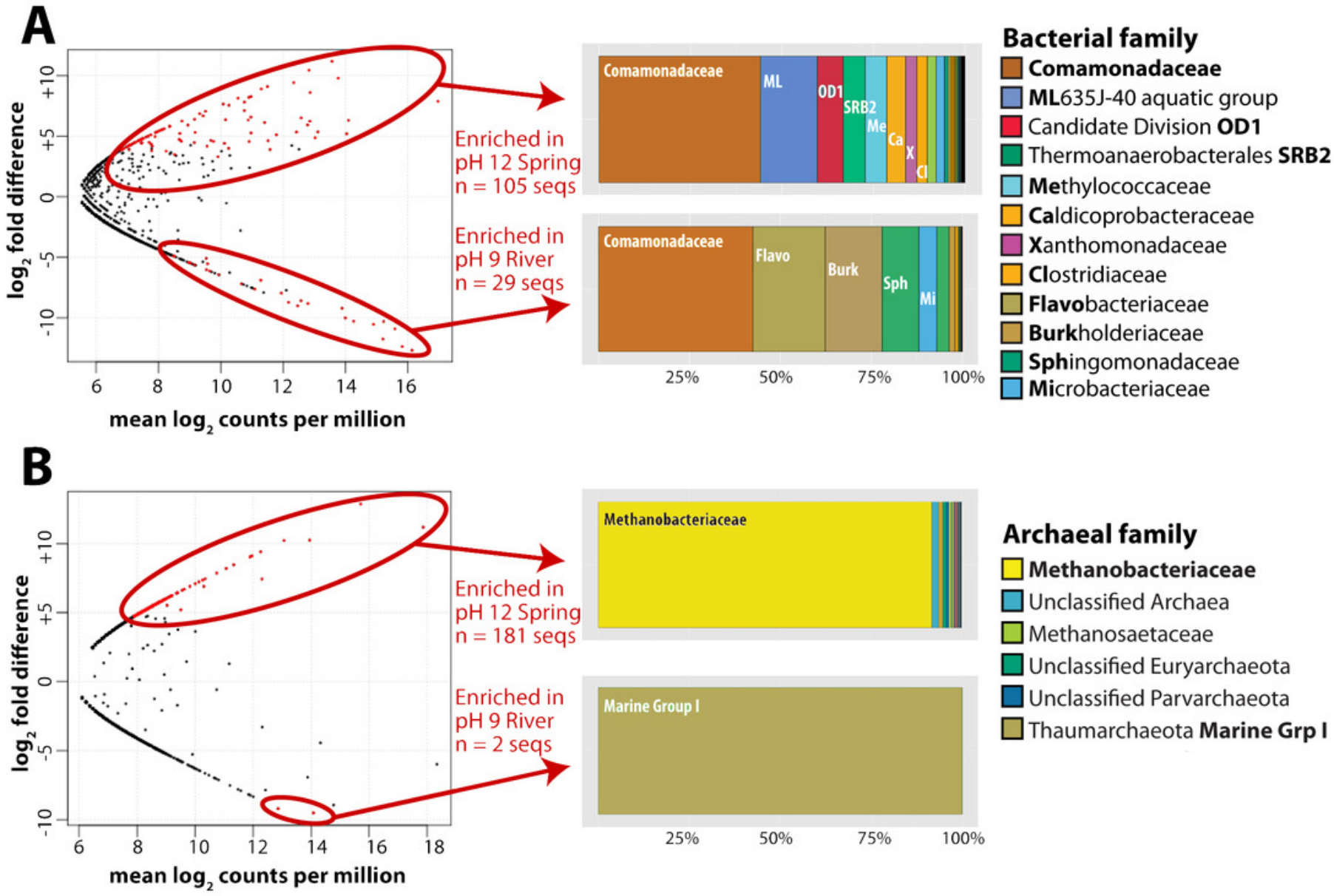


\section{Figure 3}

Predicted methanogenesis proteins in the combined-spring metagenomic assembly.

Diagram of methanogenesis pathways from carbon dioxide, formate, acetate, methanol, and methylamines with associated protein homologs identified with KEGG IDs. Green-highlighted proteins are predicted to occur in the combined-spring metagenomic assembly, and yellowhighlighted proteins are predicted to occur in both the combined-spring and combined-river assemblies. The black border indicates proteins identified in the Methanobacteriaceae bin (ESOM Bin 1 in Figure 4 and Table 5). The diagram is modified from (Ferry, 2010).

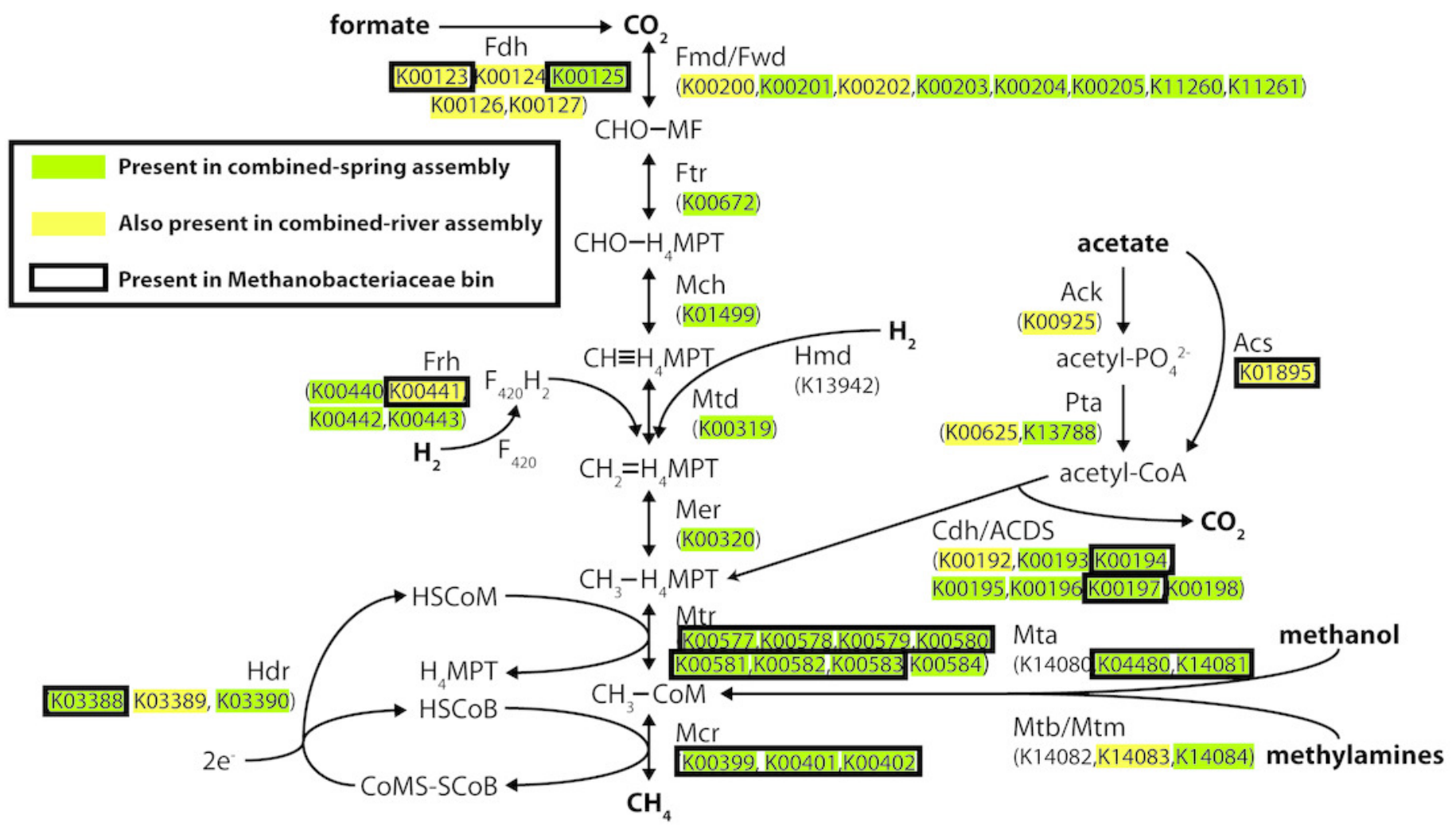




\section{Figure 4}

An emergent self-organizing map (ESOM) constructed with the combined-spring metagenomic assembly.

Each point represents a fragment of metagenomic assembly, and points are arranged in space according to the similarities of their tetranucleotide compositions. Dark gray areas are valleys where highly similar sequences cluster together. Light areas of the map are high topographic ridges that separate dissimilar sequences. The same ESOM is shown here twice: metagenomic fragments are color-coded in A) to indicate PhyloSift classifications of taxonomic markers and in $B$ ) to show which fragments are predicted to encode protein functions of particular interest to this study. Based on this information, five bins of sequences were selected from the map for further evaluation (Table 5). 

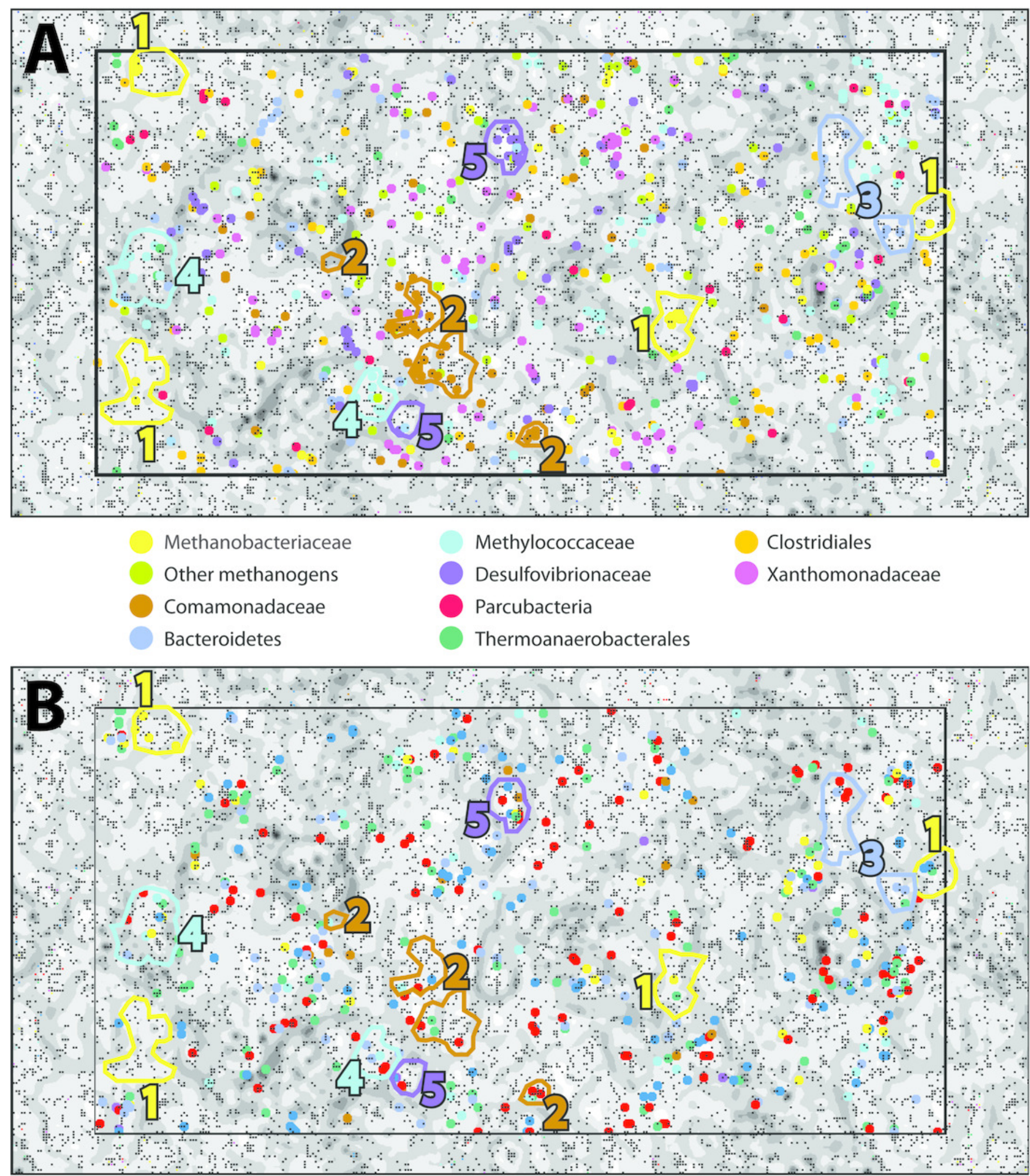

Methanogenesis

Acetate metabolism

NiFe hydrogenase

FeFe hydrogenase
Methylotrophy

Dissimilatory sulfate reduction

Pyruvate fermentation

Formate metabolism 